\title{
Especies oportunistas de importancia clínica de los géneros Bipolaris Shoemaker y Curvularia Boedijn: su caracterización bajo los nuevos criterios taxonómicos
}

(Opportunistic species of clinical relevance in the Bipolaris Shoemaker \& Curvularia Boedijn genera: its characterization under newest taxonomic criteria)

Eduardo Piontelli Laforet. Excátedra de Micología, Escuela de Medicina Universidad de Valparaíso, Casilla 92 V, Valparaíso, Chile. eduardopiontelli@hotmail.com

RECIBIDO: 16 de Noviembre de 2015

APROBADO: 11 de Diciembre de 2015

EL AUTOR DECLARA NO TENER CONFLICTO DE INTERESES

Palabras clave: Curvularia, Bipolaris, taxonomía Key words: Curvularia, Bipolaris, taxonomy

\section{RESUMEN}

Los géneros fúngicos Bipolaris y Curvularia, incluyen numerosas especies fitopatógenas, saprotrofas y algunas oportunistas emergentes en el ser humano como en otros animales. La distribución ecológica de ambos taxas es cosmopolita en la gran mayoría de sus integrantes, encontrándose frecuentemente en hojas, tallos y raíces de diferentes pastos, en especial Poaceae, pero también en una gran variedad de dicotiledoneas, aire y suelo en todos los continentes. Cochliobolus, Bipolaris y Curvularia integran un complejo de especies taxonómicamente confuso, debido a los constantes cambios en la nomenclatura de algunos de sus integrantes asexuales (Bipolaris y Curvularia), los cuales se han diferenciado principalmente en base a la morfología de sus conidios, situación a veces muy dificultosa debido a que en ambos géneros algunas especies presentan similares características conidiales. Una cuidadosa identificación y una nominación precisa de las especies es crucial para el acceso a la información referente en la literatura moderna, que gracias a la biología molecular ha resuelto muchas de las dudas de la taxonomía basada solo en el fenotipo.

Las especies de ambos géneros (principalmente Curvularia) pueden afectar a pacientes inmunocomprometidos e inmunocompetentes, en especial B. cynodontis, $\boldsymbol{C}$. australiensis $\boldsymbol{C}$. hawaiensis y $\boldsymbol{C}$. spicifera, causando cuadros clínicos diversos ya sea superficiales o profundos en muchas áreas geográficas.

Los objetivos de este trabajo solo pretenden aportar para el micólogo médico dedicado al laboratorio, los avances más significativos en la nomenclatura, taxonomía y biología molecular de las especies comunes de importancia clínica de ambos géneros. Se incluyen además como objetivo primario, descripciones, figuras, claves y la literatura actual de utilidad en la identificación de los agentes causales, sin olvidar la valoración de sus sensibilidades frente a los antifúngicos modernos. Se aconseja además, que si el laboratorio es 
Especies oportunistas de importancia clínica de los géneros Bipolaris Shoemaker y Curvularia Boedijn - E. Piontelli.

de baja complejidad, debe derivar su aislado a un centro de referencia internacional para confirmar mediante biología molecular su diagnóstico.

\section{ABSTRACT}

The fungal genera Bipolaris and Curvularia, include numerous plant pathogenic species, saprophitic and some emerging opportunistic in man and other animals. The ecological distribution of both taxa is cosmopolitan in the vast majority of its members, often being in leaves, stems and roots of different grasses, especially Poaceae, but also in a variety of dicotyledonous, air and soil on all continents. Cochliobolus, Bipolaris and Curvularia integrate a complex of species taxonomically confusing due to the constant changes in the nomenclature of some of its asexual members (Bipolaris and Curvularia), which are differentiated mainly based on the morphology of its conidia, a situation sometimes very difficult because in both genera conidial of some species have similar characteristics. Careful identification and a precise nomination of species is crucial for access to information concerning in modern literature, actually thanks to molecular biology has solved many of the doubts of taxonomy based only on the phenotype.

The species of both genera (mainly Curvularia) can affect immunocompetent or debilitate patients, especially B. cynodontis, C. australiensis, $C$. hawaiensis and C.spicifera, causing various superficial or systemic clinical cases in many geographic areas.

The objectives of this paper are intended only to provide for medical mycologist dedicated to the laboratory, the most significant developments in the nomenclature, taxonomy and molecular biology of the common species of clinical importance of both genera. Also included as a primary objective, descriptions, figures, keys and the current literature useful in identifying the causative agents, without forgetting the value of its senbility against modern antifungals.
It is also advisable, if the laboratory is low in complexity, must derive its isolated tu a international reference center to confirm the diagnostic by molecular biology.

\section{INTRODUCCIÓN}

Shoemaker (1959), estableció el género Bipolaris para las especies que Nisikado (1928) colocó en su subgenero Euhelminthosporium. Los conidios se describieron como fusoides, derechos o curvos y capaces de germinar en ambos extremos del conidio. Especie tipo: Bipolaris maydis (Nisik. \& Miyake) Shoem. Teleomorfo (= Cochliobolus). Las especies de Bipolaris Shoemaker y Curvularia Boedijn (Ascomycota, Dothideomycetes, Pleosporales, Pleosporaceae), son importantes patógenos en más de 60 géneros de plantas hospedadoras o saprotrofas (Sivanesan 1987; Rong, 2001;Schoch et al, 2009; Manamgoda et al., 2011,2012, 2014, 2015; da Cunha et al, 2012 ; Tan et al, 2014; Madrid et al, 2014), sin embargo, unas pocas especies de estos géneros son ocasionalmente causantes de infecciones oportunistas en humanos $u$ otros animales (Hoog et al. 2000-2011). Los frecuentes cambios en la nomenclatura, como resultado en los avances taxonómicos, son importantes para los micólogos de las diferentes ramas científicas, ya sea fitopatólogos o dedicados a las diferentes ciencias biológicas (Sivanesan 1987-1992; Manamgoda et al. 2011, 2012, 2014). Bipolaris y Curvularia presentan similares morfologías (Sivanesan 1987) y algunas especies de Bipolaris con conidios cortos y derechos presentan características intermedias entre éstos 2 géneros, a diferencia de las especies con grandes y largos conidios curvos (Bipolaris maydis).

Los estudios filogenéticos moleculares recientes en Bipolaris y Curvularia, demostraron que la primera no es monofilética y algunos de sus integrantes con conidios cortos y derechos se agrupan con Curvularia (Goh 1998; Berbee et al. 1999; Emami \& Hack ,2002; Manamgoda et 
Especies oportunistas de importancia clínica de los géneros Bipolaris Shoemaker y Curvularia Boedijn - E. Piontelli.

al. 2011-2012). El teleomorfo Pseudocochliobolus fue primariamente separado de Cochliobolus basándose en su morfología sexual (Tsuda et al. 1977), pero se ha tratado generalmente como sinónimo (Alcorn,1983; Sivanesan,1987). Debido a la alta variación intraespecífica de algunos caracteres encontrados, Alcorn (1983), dudó en su uso para una delineación genética debido a que ambos géneros producen estados asexuales en Bipolaris y Curvularia, lo que permitió las bases para la sinonimía entre Pseudocochliobolus y Cochliobolus.

Ecología. Las especies de Bipolaris y Curvularia se aíslan con frecuencia en hojas, tallos y raíces de diferentes pastos, algunas especies de Bipolaris y Curvularia (B. cynodontis y $C$. lunata) se encuentran en pasto bermuda y otros pastos o diversos vegetales Chloris, Cymbopogon, Cynodon, Hordeum, Oryza, Pennisetum. Saccharum, Sorgum, Zea, etc. pero también desde una gran variedad de dicotiledoneas, aire y suelo en todos los continentes (Sivanesan, 1987;Piontelli \& Grizzoli 1994; Picco et al, 1999).

Biología Molecular. Un árbol genético empleando el gen Brn1, mostró que Bipolaris se separa en 2 mayores clados con respecto a Pseudocochliobolus y Cochliobolus (Shimizu et al. 1998), mientras las cepas de Curvularia, se agrupan solo en el grupo 2 (Berbee et al. 1999). Un análisis filogenético en las Pleosporaceae por Kodsueb et al. (2006), revelaron que Cochliobolus y sus anamorfos se dividen ampliamente en 2 grupos: Bipolaris y Curvularia con su teleomorfo común (Cochliobolus), lo que ha sido la causa de confusiones por la ausencia de una clara distinción morfológica entre los géneros asexuales, donde algunas especies muestran una morfología bastante semejante. Manamgoda et al,(2012; 2014), al investigar este complejo mediante un set de extipos de cultivos, junto a algunos del norte de Tailandia, empleando la combinación de análisis de genes de DNAr, ITS GPDH (gliceraldehido 3-fosfato dehidrogenasa), LSU (subunidades largas) y EF1- $\alpha$ (factor de translación y elongación 1- $\alpha$ ), mostraron también que este complejo genérico se divide en 2 grupos. Las especies de Bipolaris y Cochliobolus se agrupan en el Grupo 1 junto a sus tipos especies, mientras las especies de Curvularia (incluyendo especies llamadas como Bipolaris, Cochliobolus y Curvularia), se agrupan en el Grupo 2 con sus tipos genéricos, resolviéndose el conflicto en la nomenclatura y transfiriendo algunas especies de Bipolaris a Curvularia (19 Bipolaris, 25 Cochliobolus y 12 Curvularia). Sin embargo, existen 95 especies de Bipolaris, 30 de Cochliobolus y 101 de Curvularia que no han sido secuenciadas y por ende no adscritas a sus nuevas posibles especies, para clarificar su posición. Tazick \&, Tajick (2013), al emplear datos de análisis de multigenes, obtuvieron similares resultados y confirmaron la correcta posición evolutiva y el estatus taxonómico de Bipolaris oryzae. Managmoda et al. (2014), agregan C.spicifera (=B. spicifera), sin embargo, secuencias adicionales como la calmodulina (cmd), el factor de elongación y translación $1 \alpha$ (tef), tubulina (tub) y los espacios intergénicos del DNAr (IGS), pueden emplearse en el análisis. Por lo tanto, las secuencias de ITS + tef + tub + RAPD + IGS se combinan en una matriz de datos, los cuales se analizan empleando el método MrBayes (Huenselbeck \& Ronquist, 2001; Gomez

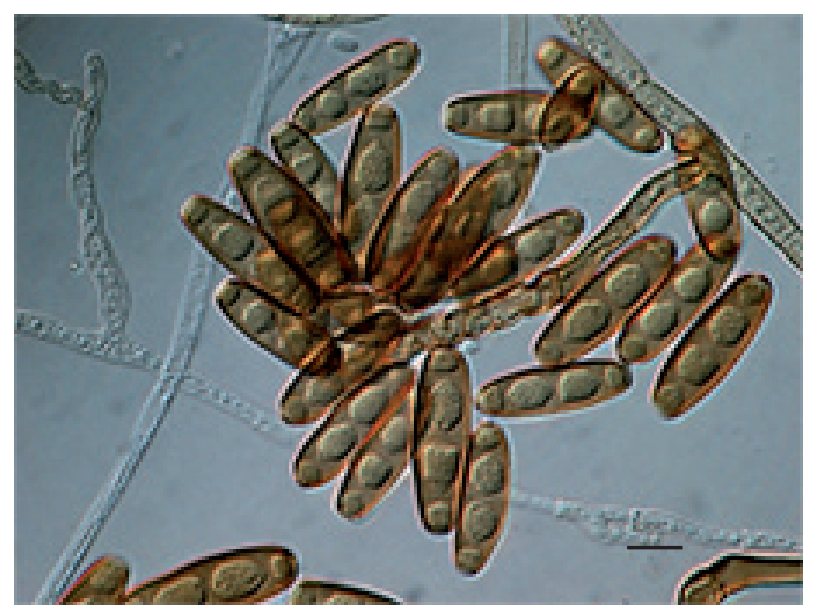

Figura 1. Curvularia australiensis (= Bipolaris australiensis), conidios y conidióforos (Barra 10 $\mu \mathrm{m})$. 
Especies oportunistas de importancia clínica de los géneros Bipolaris Shoemaker y Curvularia Boedijn - E. Piontelli.

et al, 2005). En la filogenia estimada, los aislados de Curvularia sp., C. hawaiiensis, C.australiensis y $C$. spicifera se agrupan en 4 distintos clados. Aunque C. australiensis y C.spicifera pueden ser separadas en este filograma, la respuesta en relación a cuan distintas son estas dos especies o si corresponden a dos variedades de la misma especie, queda sin resolver (Magnamoda et al, 2012, Jean et al, 2015).

Nomenclatura Taxonomía y oportunismo en humanos. El nombre Bipolaris, se emplea mucho más en la literatura que Cochliobolus en especial para los fitopatólogos, por ende, parece aconsejable conservar el nombre genérico Bipolaris Shoemaker (1959) sobre Cochliobolus Drechsler y conservar el nombre Bipolaris maydis sobre Cochliobolus heterostrophus, basándonos en el nuevo código de los hongos (Vea: Rossmann et al), (2013; Nalin et al, 2014). Los estados sexuales de Curvularia y Bipolaris incluidos en Cochliobolus, presentan estructuras con un ascoma ostiolado con seudoparáfisis y ascos bitunicados, que contienen ascosporas multiseptadas y filiformes, las cuales se presentan reunidas más o menos en forma helicoide dentro del asco (Sivanesan 1987, Zhang et al. 2012). Pseudocochliobolus, un género similar fue segregado por (Tsuda et al. 1977, Tsuda \& Ueyama 1981) de Cochliobolus, para acomodar las especies que producen ascomas en estromas columnares, con ascosporas dispuestas linearmente o laxamente enroscadas en los ascos y los estados asexuales asociados que no incluyen las especies de Curvularia y Bipolaris que presentan conidios cortos y más bien derechos. Muchos autores no han aceptado Pseudocochliobolus como un taxa adicional separado, argumentando que el grado de enroscamiento de las ascosporas puede variar ampliamente entre las especies, introduciendo una complejidad innecesaria en la taxonomía del grupo. Dennis, 1978; Barr 1979; Alcorn, 1988; Sivanesan 1984-1987, colocan ambos estados sexuales y asexuales en las Pleosporales y la biología molecular confirma este orden y en forma más precisa en la gran familia de las Pleosporáceae, donde pertenecen importantes fitopatógenos y relevantes hongos clínicos tales como: Alternaria y Exserohilum (Olivier et al. 2000; Zhang et al. 2009- 2012). Manamgoda et al.(2012), en una revisión extensa de especies y mediante análisis de ITS, la gran subunidad (LSU) rDNA, GPD y el gen del factor de elongación $1-\alpha($ EF1- $\alpha)$, confirman la existencia de los mismos 2 grupos reportados por Berbee et al.(1999) y puso en sinonimía Cochliobolus y Pseudocochliobolus con el nombre genérico más usado Bipolaris y Curvularia respectivamente, expandiendo además el concepto de Curvularia para acomodar algunas especies con conidios más bien derechos formalmente incluidos en Bipolaris, pero que se agrupaban en el clado Curvularia, incluyendo importantes agentes de enfermedades oportunistas en vertebrados (B. australiensis, B. hawaiiensis y B. spicifera (de Hoog et al. 2000), el ultimo género considerado anteriormente como Curvularia por Boedijn (1933). Las especies del género Curvularia se han identificado mayormente mediante morfología, sin embargo, los nombres aplicados a menudo no se correlacionan con las identificaciones en bases de secuencias de DNA. Tal es el caso de C. lunata que parece ser un complejo de (Berbee et al. 1999, Yanagihara et al. 2010). Da Cunha et al. (2013), recientemente caracterizaron mediante secuencias de 4 loci un set de 99 aislados de Curvularia en clínica (USA), pudiendo identificar el $73.2 \%$ de los aislados, incluyendo C. aeria (la más común), seguida de C.geniculata/senegaliensis, C.lunata, C.verruculosa, C.protuberata. Tres especies aisladas, fueron clasificadas morfológicamente por faltas de cepas de referencia y secuencias conseguibles como: $C$. intermedia, $C$, sorghina y C. clavata. Algunas especies que se han descrito desde humanos, también se han reportado desde material vegetal ya sea como patógenas o saprotrofas, tales como: C. asianensis, C. borreriae, C. hominis, C.muehlen-beckiae, $C$. trifolii y $C$. verruculosa (Manamgoda et al, 2015). Los remanentes aislados se distribuyeron en 3 diferentes linajes (I-II-II) que 
Especies oportunistas de importancia clínica de los géneros Bipolaris Shoemaker y Curvularia Boedijn - E. Piontelli.

no se correlacionan con ninguna especie conocida. Posteriormente Madrid et al, (2014), estudiaron mediante morfología y filogenia estos 3 linajes, describiendo 5 nuevas especies (C. americana, $C$. chlamidospora, C. hominis, C. muehlenbeckiae, C. pseudolunata)(vea también para Curvularia da Cunha, 2014).

\section{Descripción del género Bipolaris}

Especie tipo: Bipolaris maydis (Y. Nisik. \& C. Miyake) Shoemaker.

Micelio hialino, café pálido, gris o negro. Colonias de crecimiento rápido, grises a gris oscuro, con micelio aéreo generalmente algodonoso. Descripción del teleomorfo (cochliobolus morph): Ascomata de hasta $700 \mu \mathrm{m}$ diám. incrustado o superficial, libre o en un estroma plano, generalmente globoso a elipsoidal, a veces ampuliforme o aplanado, que se forma en un sustrato duro del hospedador, liso o cubierto con filamentos vegetativos, ostíolo central, a menudo papilado o con un cuello que puede ser subcónico o cilíndrico. Peridio de células seudoparenquimatosas, con células de igual grosor o levemente gruesas en el ápice. Hamathecium que contiene seudoparáfisis septadas, filiformes, y ramificadas, con ascos con 2-8 esporas, clavadas, cilíndricas-clavadas o ampliamente fusoides, derechas o levemente curvas, de paredes delgadas, bitunicadas (fissitunicadas), a menudo se hacen más alargadas antes de la dehiscencia, cortamente pediceladas y redondas en los ápices. Ascosporas fasciculadas, filiformes o flageliformes, hialinas o a veces amarillo pálido o café pálido al madurar, septadas, enrolladas levemente o fuertemente en el asco, a veces con extremos libres y a menudo con una vaina mucilaginosa.

Anamorfo. Conidióforos únicos, ramificados y a veces dispuestos en pequeños grupos, derechos o flexuosos, a veces geniculados. Nodos conidiógenos lisos, verrugosos u obclavados. Conidios generalmente curvos, en forma de canoa, fusoides u obclavados, raramente derechos, 2-14 pseudoseptos (usualmente más que 6), hialinos a fuerte- mente oliváceos, que germinan por la producción de 2 tubos germinales polares, uno desde el ápice y el otro cercano a la cicatriz. (Shoemaker, 1959; Sivanesan, 1987, Alcorn 1988, Managmoda et al, 2013-2014).

El género contiene unas 50 especies dispersas en zonas tropicales y subtropicales (Managmoda et al, 2014.

La morfología de las especies de Bipolaris debe ser reservada para las especies que presentan mitosporas en forma cilíndrica o elipsoide-fusoide con su parte más ancha cerca del medio o hacia la base, con un largo por ancho de 5 o más veces. Las especies donde sus mitosporas se estrechan prominentemente hacia el ápice, deben considerarse en Bipolaris. Estas especies tienen una preferencia por hospedadores graminícolas. La formación del tubo germinal en ambos polos o en uno solo, puede observarse mediante un procedimiento simple como colocar una gota de medio de cultivo líquido nutritivo sobre un portaobjeto, agregarles una cantidad de mitosporas con el asa y luego cubrir con cubreobjeto. Se incuba a $25^{\circ} \mathrm{C}$ por $12-24 \mathrm{~h}$ en cámara húmeda y se observa al microscopio. La presencia mediana del primer septo conidial, puede observarse en los cultivos jóvenes, revisando el nacimiento de los más nuevos. La más clara separación entre Bipolaris y Exerohilum es el protuberante hilum de las mitosporas en este último, sus acentuados distoseptos y su diferente teleomorfo en Setosphaeria. La fuerte similitud entre Curvularia y Bipolaris en algunas especies, indica más bien una unidad que una heterogeneidad y la presencia de un solo teleomorfo (Cochliobolus) para ambos géneros no es algo nuevo en las Pleosporaceae (Sivanesan, 1984; Kirk et al, 2008).

En el complejo Bipolaris-Curvularia, los aspectos morfológicos más importantes para la delimitación genérica de sus miembros consiste en: la presencia en Curvularia de una célula muy abultada y oscura con relación a las restantes, la forma predominante de los conidios y la presencia de septos verdaderos. Las especies de Bipolaris 
que poseen pocos distoseptos, están más relacionadas con las especies de Curvularia que aquellas que presentan muchos. También se ha demostrado que además de los caracteres morfológicos, son de gran ayuda los culturales y biológicos como el aspecto y crecimiento lineal de las colonias y su esporulación (Mena Portales 2004).

\section{Descripción del género Curvularia}

Especie tipo C.lunata (Wakker) Boedjin

Morfológicamente Curvularia se caracteriza por la producción de conidióforos simpodiales con células conidiógenas tréticas (poro), terminales e intercalares que dan origen a conidios elongados y transversalmente septados con una cicatriz basal oscura. Los conidios son a menudo curvos y asimétricamente dilatados en su célula intermedia, sin embargo, se han descrito especies con conidios derechos (Sivanesan 1987). Autores tales como: Ellis (1971, 1976), de Hoog et al. (2000) and Revankar \& Sutton (2010), han descrito los conidios como verdaderamente septados o 'euseptados'o sea, compuestos de una sola pared con septos que se han formado de la extensión interna de ésta (Luttrell 1963). Un género similar es la especie tipo de Bipolaris (B.maydis), que tradicionalmente se distingue de Curvularia por producir conidios que carecen de una célula brotante intermedia asimétrica y 'distoseptada' (Domsch et al. 2007; Revankar \& Sutton 2010), con una pared común externa que encierra una célula más o menos esférica, cada una de las cuales es rodeada por una pared individual (Luttrell 1963). La separación de los 2 géneros ha sido controversial en la literatura, sin embargo muchos autores han comprobado que las especies de Curvularia, también presentan conidios distoseptados (Alcorn, 1983; Sivanesan,1987; Seifert et al, 2011; Madrid et al, 2014).

\section{Metabolitos secundarios y toxinas}

Las toxinas producidas por algunas especies de Bipolaris, pueden ser hospedador específicas o no específicas. B.victoriae, produce victorina una potente toxina, B.carbonum produce la toxina $\mathrm{HC}$ (un potente polipéptido), B. sacchari produce una toxina HS (helmintosporosina) y B.maydis la toxina $\mathrm{T}$, todas ellas específicas para su hospedador. B. oryzae, es el agente de la mancha café del arroz y su toxina la ofiobolina (terpenoide), es capaz de producir parte de los síntomas de la enfermedad. Cuando las células epidérmicas del arroz se ponen en contacto con la toxina, se presenta generalmente una acumulación de polifenoles, activándose varias polifenolasas. Estos cambios en el metabolismo fenólico, son parte de la inducción de los síntomas de la enfermedad y la oxidación de los fenoles produce las manchas café. Esta toxina produce además otros síntomas (ver: Goodman t al.,1986; Carson et al, 1991; Franco \& Zavaleta, 2001; ). Bipolaris maydis y taxas relacionados, son conocidos por su habilidad para producir selectivas toxinas (HSTs), un grupo de compuestos con diversos pesos moleculares, que sirven como factores de virulencia o de patogenicidad.

\section{Examen microscópico de los ejemplares y me- dios de cultivo}

Los cultivos obtenidos de fuentes vegetales diversas u otras en estudio, son muy útiles, si se presenta poca esporulación o los cultivos empleados tienen más de 20 días, es preferible transferir las muestras a placas con agar agua (TWA) y fragmentos esterilizados de paja de trigo (Triticum aestivum), como también Sorghum halepense (Nombre común: cañota, hierba Johnson, paja Johnson (Ve), zacate Jonhson, pasto silvestre, sorgo silvestre, sorgo de Alepo). Pueden emplearse también tallos de Urochloa maxima (Colonial, guineo, hoja fina, pasto guineo, privilegio, rabo de mula, zacatón, panizo de guinea, pasto Tanzania).

El material vegetal a usar para la buena producción del anamorfo o teleomorfo (menos frecuente) en cultivo, puede preparase de diversas maneras: en autoclave o por esterilización superficial con cloro al 3-5\% durante 5 minutos y luego 3 lavados con agua estéril. Las preparaciones 
microscópicas deben realizarse a partir de colonias con 10 días de crecimiento a $20-26^{\circ} \mathrm{C}$ en oscuridad, bajo luz fluorescente o UV (12 horas de claridad y 12 de oscuridad) (Sivanesan,1987). Pueden emplearse también agar papa zanahoria o agar avena, así como PDA en cultivos de 10 - 20dias a $25^{\circ} \mathrm{C}$ en oscuridad. Los medios pobres son los mejores en la fructificacion así como los trozos esterilizados de vegetales mencionados.

Los ejemplares se examinan bajo lupa estereoscópica para detectar los conidióforos y conidios. Las preparaciones permanentes se efectúan en diversos medios de montajes: alcohol polivinilo o lactofenol con azul de algodón. Las preparaciones con alcohol polivinilo se colocan en estufa durante 48 horas a $40{ }^{\circ} \mathrm{C}$, para su sellado definitivo. Las con lactofenol, se pueden sellar con esmalte de uñas incoloro $u$ otros sellantes.

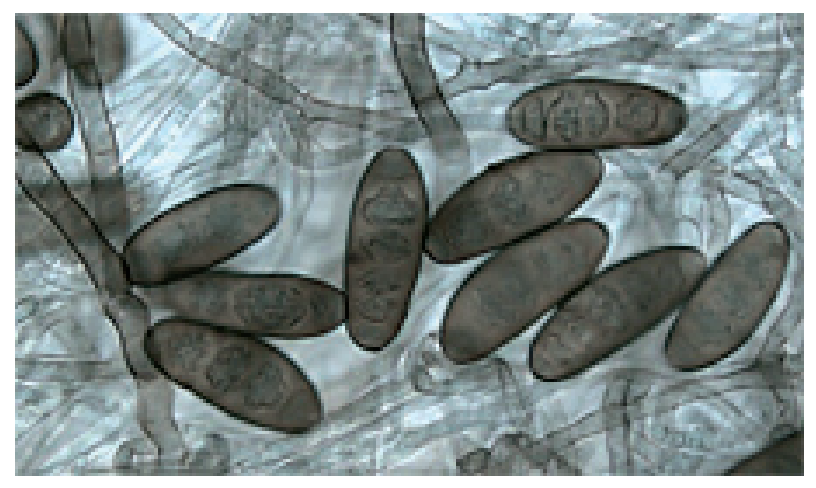

Figura 2. Curvularia spicifera (= Bipolaris spicifera) conidióforos y conidios (Figura tomada de:www. windows search-exp.com).

\section{Bipolaris como agente causal de enfermedades oportunistas en humanos}

Las especies de Bipolaris o Curvularia que usualmente se reconocen como saprotrofas o fitopatógenas, pueden afectar a pacientes principalmente con compromiso inmune o inmunocompetentes, en especial: C.australiensis, C.hawaiiensis y C.spicifera (Fig.2) (Adam et al., 1986; Walsh, \& Groll, 1999; Schell, 2000; Buzina, et al., 2003; El Khizzi et al., 2010; Krizan, (2012); Minkler et al, 2014). Éstas se diferencian morfológicamente por el tamaño de los conidios y el número de distoseptos (los pseudo-septos son aquellos donde solo la pared interna de la pared está comprometida). Las especies de Bipolaris, Curvularia y Exserohilum son agente causantes de faeohifomicosis, considerada en la actualidad como micosis emergente por hongos filamentosos en humanos y otros animales. Estas infecciones que incluyen hongos pigmentados deben separarse de aquellas donde los tejidos involucrados presentan granos (micetoma micótico) o cuerpos esclerotiales (Cromoblastomicosis).

Las micosis broncopulmonares alérgicas consisten en enfermedades pulmonares de hipersensibilidad que presentan alta distribución mundial, causadas por múltiples etiologías donde Aspergillus fumigatus es el agente etiológico más común, pero también Curvularia hawaiiensis puede causarla en pacientes pediátricos (Chowdhary et al. 2011). Algunas especies del género Bipolaris, en especial, son agentes causantes de varios tipos de faeohifomicosis. El espectro clínico es diverso e incluye desde: sinusitis alérgicas invasivas y crónicas, queratitis, endoftalmitis, endocarditis, endoarteritis, osteomielitis, meningoencefalitis, peritonitis, otitis media (en trabajadores agrícolas), fungemia así como infecciones cutáneas y pulmonares, junto a enfermedades broncopulmonares, diálisis peritoneal asociada a peritonitis. Bipolaris, puede infectar ya sea individuos inmunocompetentes o con compromiso inmune (McGinnis et al, 1986; Strada et al, 1986; Adam et al, 1986; Marcus et al ,1992; Stringer \& Riyan. 2000; de Hoog et al, 2000; Buzina et al, 2003; Castelnuovo et al, 2004; Pimentelet al,2005; Kobayashi et al, 2008; Revankar \&. SuttoN, 2010; Da Cunha et al, 2012). Los casos más frecuentes se deben a Curvularia spicifera que generalmente coloniza frecuentemente los senos nasales en áreas de climas cálidos (Buzina et al ,2003). Schubert (2001), hizo las mismas observaciones, reportando $C$. spicifera como la causa más común de sinusitis alérgica en el sudeste de USA. Con una incidencia mayor si se compara con Europa, donde Bipolaris se encuentra 
en menor proporción (Ebner et al, 1989). En un estudio reciente sobre biodiversidad de presencia en el mucus nasal de 234 pacientes con rinosinusitis crónica, C.hawaiiensis fue aislada en 2 pacientes y $C$. australiensis en uno; estos pacientes fueron analizados en el medio Oeste y la india (Buzina et al, 2003).

En un set de 104 aislados clínicos, por da Cunha et al, (2012), la especie dominante fue $C$. spicifera $(67.3 \%)$, seguida por C. hawaiiensis $(18.2 \%), B$. cynodontis (8.6\%), B. micropus (2.9\%), C. australiensis (2\%), y B. setariae (1\%).La correlación entre la identificación morfológica y molecular fue de $89.7 \%$ (bastante aceptable).

\section{Descripción de la especies comunes en clínica del genero Bipolaris y Curvularia}

1. Bipolaris cynodontis (Marignoni) Shoemaker (Fig.3) = Helminthosporium cynodontis Marignoni = Drechslera cynodontis (Marignoni) Subram. \& B.L. Jain = Cochliobolus cynodontis R.R. Nelson

Colonias en PDA, blancas en juventud, tornándose gris a negro al madurar. Puede presentar la forma asexual en PDA: Conidióforos (43-)60145(-160) x 4-6 (-8) $\mu \mathrm{m})$, que se proyectan únicos o en pequeños grupos, ramificados, septados, derechos o flexuosos, geniculados en su parte superior, café a oliváceos café. Nudos conidiógenos café oscuros, levemente verrugosos bajo los nudos. Conidios (27-) 40-80(-100) x(10-)12-18(-20) $\mu \mathrm{m}$, lisos a levemente curvos o derechos, cilíndricos a elipsoidales, de color hialino cuando inmaduros, que se tornan oliváceos verdes y en el tiempo café a

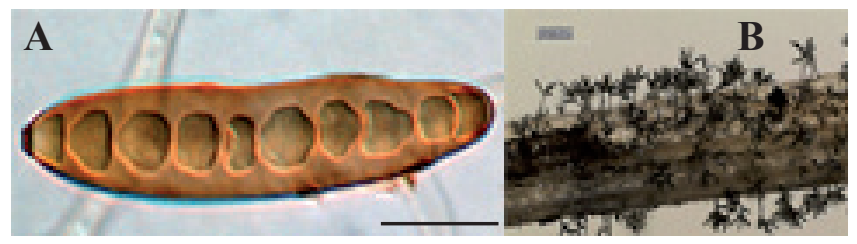

Figuras 3. A. Bipolaris cynodonti, conidios (Barra $20 \mu \mathrm{m}$ ), B. Conidióforos y conidios en sustrato natural (Tomado de: http://micologia.mcnetworks.org/). café dorado cuando maduros,(3-)7(-9) distoseptos. Hilum inconspicuo o levemente protuberante 3-4 $\mu \mathrm{m}$ de ancho. Ontogenia del primer septo, generalmente basal, raramente mediano, segundo septo distal. Germinación conidial bipolar, con la célula final a veces brotante, para formar una vesícula globosa delgada, desde donde se origina un tubo germinativo.

La forma sexual en agar Sach's con hojas de Zea mays: Ascomata 300-450 x 200-400 $\mu \mathrm{m}$, negro globoso o elipsoidal, con largas setas café y conidióforos con conidios que se desarrollan en la parte alta del ascoma. Cuello ostiolar subcónico 30-90 $\mu \mathrm{m}$ largo con una masa de células hialinas en su parte superior. Seudoparáfisis, hialinas, septadas, filamentosas. Ascos 130-210 x 16-28, que se producen entre las seudoparáfisis, que nacen desde la base del lóculo. Ascos, 160-320 x 5-10 $\mu \mathrm{m}$, con 1-8 ascosporas enroscadas en una apretada hélice, cilíndricas o clavadas, derechas o levemente curvas. Ascosporas filiformes a flageliformes, a veces adelgazándose en los extremos, ascosporas maduras típicamente hialinas, 3-9 septos después de madurar, ascosporas a menudo rodeadas con una fina capa de mucus. Germinación ya sea terminal como lateral. Especie heterotálica.

Distribución: aparentemente cosmopolita.

Bipolaris cynodontis es considerada un patógeno secundario o saprófito en un amplio rango de hospederos vegetales. No se le conoce ser causa de serias enfermedades en éstos, salvo produciendo manchas en las hojas en Cynodon dactylon (Datnoff \& Rutherford 2004, Hagan 2005). En clínica se describe raramente. Una fitotoxina llamada bipolaroxina se produce por las cepas de esta especie. B. cynodontis muestra un amplio rango de medidas en los conidios y conidióforos.

La brotante célula final de la germinación del conidio, es una estructura característica a considerar. Acorde a los datos filogenéticos, $B$. cynodontis es altamente similar a B. coffeana. Sin embargo, para evitar confusiones, Manamgoda et al. (2014), las consideran especies distintas. 
2. Bipolaris setariae (Sawada) Shoemaker (Fig. 4) Sínónimo básico: Helminthosporium setariae Sawada, Bull. = Drechslera setariae (Sawada) $\mathrm{Su}-$ bram. \& B.L. Jain, = Helminthosporium setariae Lind. = Ophiobolus setariae S. Ito \& Kurib.(fide Sivanesan 1987) $=$ Cochliobolus setariae (S. Ito \& Kurib.) Drechsler ex Dastur,

Morfo asexual en Setaria italica: Conidióforos (96-) 145-207(-218) x 4-6 $\mu \mathrm{m}$, café pálido a oliváceo café, que nace único o en pequeños grupos, septado, derecho o flexuoso, a veces geniculado en la ultima parte, cilíndrico, célula basal brotante. Nodos conidiógenos café oscuros. Conidios (50) $65-100(-108) \times(10-) 13-16 \mu \mathrm{m}$, derechos o curvos, fusoides o naviculares, café pálidos a dorados café, con (5-)8(-10)-distoseptos. Hilum inconspicuo o ligeramente protuberante. Germinación en ambos polos del conidio. Morfo sexual en agar Sach's: Ascomata negro 240-505 x 220-315 $\mu \mathrm{m}$, café, globosos o cortamente elipsoidales, seudoparenquimatosos. Cuello ostiolar 60-125 x 50-110 $\mu \mathrm{m}$, paraboloide, cilíndrico. Ascos 130-150 x 22$32 \mu \mathrm{m}$, numerosos, fusiformes, derechos o levemente curvos anchos a veces bajo la mitad, con ápices redondos, cortamente estipitados, hialinos, de paredes delgadas con 1-8 esporas. Ascosporas 200-315 × 6-7 $\mu \mathrm{m}$, hialinas o con tonos oliva, filiformes, con puntas obtusas en ambos extremos, 5-9 septos, enroscadas en una hélice cerrada (modificado de Ito 1930). Distribución: Australia, Canadá, China, Egipto, Etiopía, India, Korea, Myanmar, Nueva Zelanda, Pakistán, Perú, Sierra Leona,

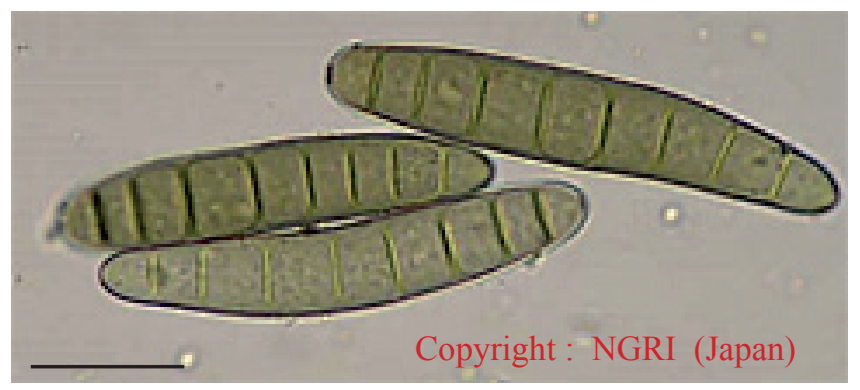

Figura 4. Bipolaris setariae. Conidios y seudoseptos (Barra $20 \mu \mathrm{m})$.
Taiwán, Turquía, Uganda, USA, Venezuela (Farr \& Rossman 2013).

\section{Bipolaris micropus(Drechsler) Shoemaker} (Fig. 5) = Helminthosporium micropus Drechsler = Drechslera micropus (Drechsler) Subram. \& B.L. Jain, = Drechslera micropa (Drechsler) Subram. \& B.L. Jain

Conidióforos solitarios o en pequeños gru-

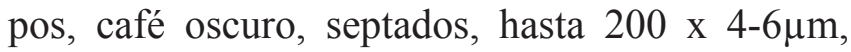
Conidios subhialinos a levemente fuliginosos, derechos o a veces levemente curvados, que se angostan lentamente hacia el ápice desde el centro, cilíndricos a elipsoidales, con célula basal obcónica con un corto hilum protuberante, 3-9 distoseptos, constreñidos en los septos, lisos, 28-92 x 10-18 $\mu \mathrm{m}$. Germinación por la célula polar. Primer septo se forma cerca de la base del conidio, como las especies de Exserohilum.

Distribución limitada: USA, India, Japón, Nueva Zelanda.

Nota: Manamgoda et al. (2014), consideran que el hilum protuberante corto, no se observa en otras especies de Bipolaris y la formación del primer septo basal se presenta en las especies de Exserohilum, situación que podría considerarse para incluirlo en este género (son necesarios mayores datos moleculares).

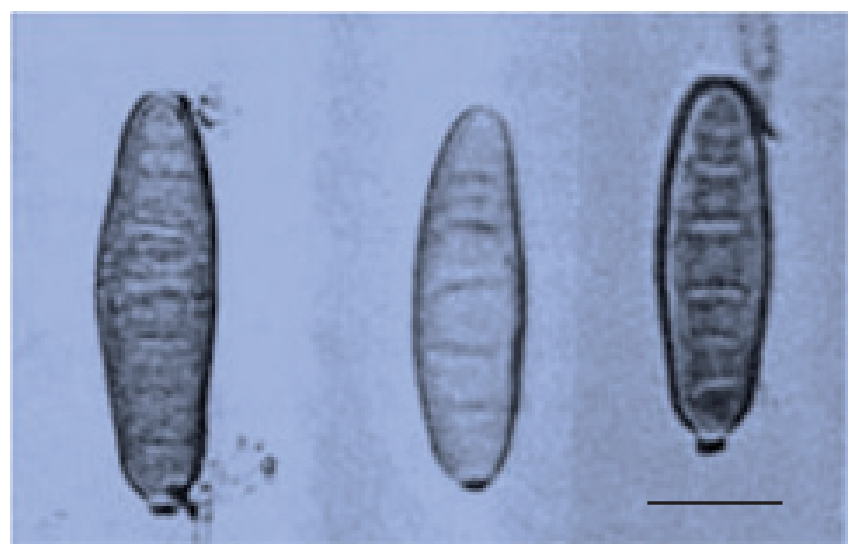

Figura 5. Bipolaris micropus, conidios con un corto hilum protuberante. (Tomado de: Sivanasan 1987) Barra $10 \mu \mathrm{m}$. 
Especies oportunistas de importancia clínica de los géneros Bipolaris Shoemaker y Curvularia Boedijn - E. Piontelli.

4. Curvularia americana Da Cunha, Madrid, Gené, Cano sp. nov. Persoonia 33:48-60 (2014) (Fig. 6)

Colonias en agar avena y papa-zanahoria con un diámetro de 62 y $69 \mathrm{~mm}$, respectivamente en 7 días a $25^{\circ} \mathrm{C}$, funiculosas y gris verdosas a verde oscuro en el centro, efusas con tono gris blanco hacia la periferia y un margen fimbriado, reverso oliva a verde oscuro. Hifas vegetativas septadas, ramificadas, subhialinas a café, lisas a asperuladas, 1,5-4 $\mu \mathrm{m}$, anastomosadas. Conidióforos semi a macronematosos, mononematosos, septados, usualmente únicos, levemente geniculados, subhialinos a café oscuro, lisos a asperulados, con la pared celular a menudo más gruesa que las de las hifas vegetativas, $60-299 \times 2-5 \mu \mathrm{m}$. Célula conidiógena terminal o intercalar, politrética, que prolifera simpodialmente, subcilíndrica a levemente brotante, 8-22 x 4-8 $\mu \mathrm{m}$. Conidios 4(-5) células, derechos a levemente curvos, 13-28 x7-15 $\mu \mathrm{m}$, usualmente con la tercera célula más inclinada y más grande que las demás, con la segunda y tercera célula café pálido a café, y la apical y basal subhialinas , célula apical de pared lisa, la intermedia lisa (levemente verrugulosa al SEM), célula basal a menudo verrugulosa; hilum no protuberante, plano, oscurecido y engrosado, 1,5-3 $\mu \mathrm{m}$ de ancho. Microconidiación a veces presente, formando 1 célula, café pálida, con conidios globosos, 5-6 $\mu \mathrm{m}$ de ancho. Clamidosporas no observadas. Teleomorfo no observado.

Nota. C. amaricana es similar a C.lunata y C.prasadii en la morfología del conidio, sin embargo, los conidios de C.lunata son hasta de 13 $\mu \mathrm{m}$ de ancho (Manamgoda et al, 2012), mientras en contraste con C.americana, todos los septos de los conidios de C.prasadii son hasta 2,4 $\mu \mathrm{m}$ de ancho (Mathur \& Matur, 1959, Ellis, 1971). El estudio filogenético coloca a C.lunata y C.prasadii en el clado, lunatus, linaje relativamente distante de C.amaricana (Madrid et al, 2014). El árbol de 4 locus, indica que $C$. americana es el taxón hermano de C.verruculosa, pero estas especies son separadas por una considerable distancia genética.
Además los conidios de $C$. verruculosa son levemente más grandes $(20-40 \times 12-17 \mu \mathrm{m})$ que los de $C$. americana y muestran una célula intermedia distintamente verrugulosa (Ellis, 1971; Sivanesan, 1987).

Distribución: USA.

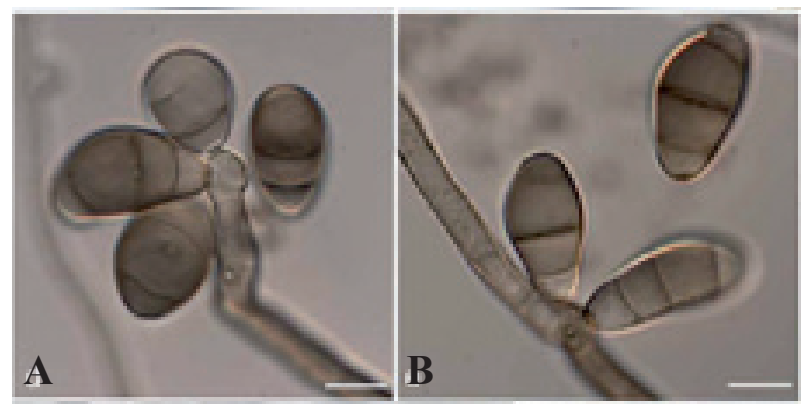

Figuras 6. Curvularia americana, A-B. Conidióforos y conidios (Tomado de : Madrid et al, 2014). Barras $10 \mu \mathrm{m}$.

5. Curvularia australiensis (M.B. Ellis) Manamgoda, L.Cai. \& K.D. Hyde, comb. nov. (Fig. 1,7) = Drechslera australiensis Bugnic. ex M.B. Ellis, = Bipolaris australiensis (M.B. Ellis) Tsuda \& Ueyama, = Pseudocochliobolus australiensis Tsuda \& Ueyama, Non Cochliobolus australiensis (Tsuda \& Ueyama)

Colonias en PDA inicialmente blancas, pero después de 3 días se tornan grises a café negruzcas, efusas, aterciopeladas y negras en el reverso. Conidióforos septados, solitarios, únicos o ramificados, geniculados y simpodiales, lisos, café rojizos, 95-205 mm de largo, con una media de 142 $\mathrm{mm}$ y 3-7 $\mu \mathrm{m}$ de ancho (media de $5 \mathrm{~mm}$ ). Conidios derechos, elipsoidales u oblongos, redondeados en los extremos, café pálidos a rojizos, mayormente con 3 pseudoseptos (raramente 4-5), mayormente 15-40 x 6,5-10 $\mu \mathrm{m}$ (media $32 \times 9 \mu \mathrm{m})$. Un hilum plano se observa en las células basales.

Es una especie heterotálica y el teleomorfo se obtiene mediante el cruzamiento de pares opuestos compatibles. Distribución: cosmopolita Nota. Cochliobolus australiensis fue revisado a la luz de las evidencias que Tsuda \& Ueyema (1981), 


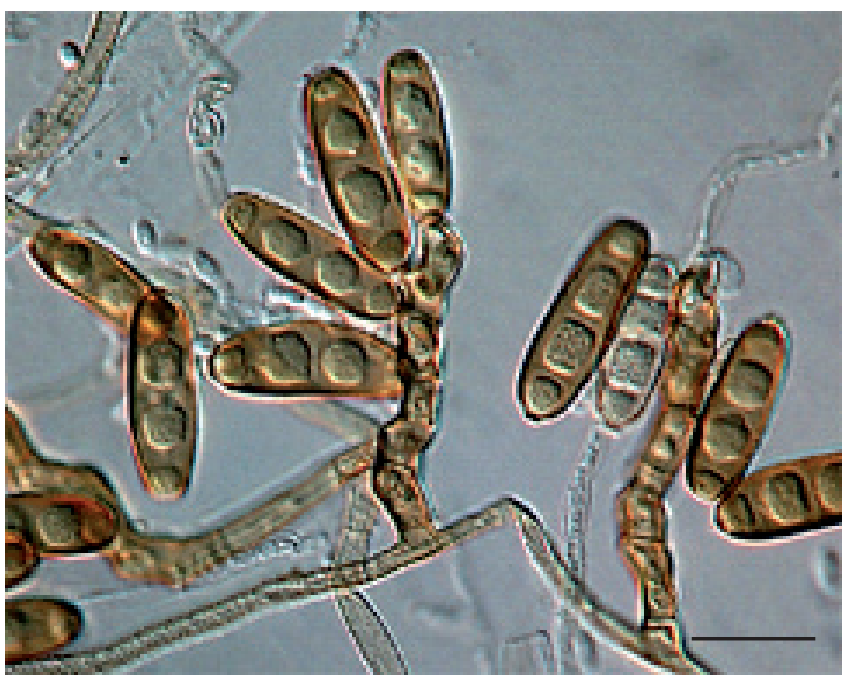

Figura 7. Curvularia australiensis, conidióforos y conidios (Barra $20 \mu \mathrm{m})$.

no examinaron un autentico aislado de Drechslera australiensis cuando establecieron Pseudoochliobolus australiensis para su morfo sexual. Deng et al,(2015), observaron por filogenia molecular que P.australiensis representaba una nueva especie de Curvularia, distinta de C. australiensis y que llamaron C.tsudae (Tsuda \&Ueyama), H.deng, Y.P Tang \& R.g.Shivas. Esta especie difiere de C. australiensis por sus conidios que son siempre con 3 distoseptos y un promedio de $26 \mu \mathrm{m}$ de largo, mientras C.australiensis tiene 3 o raramente 4-5 septos y una media de $32 \mu \mathrm{m}$ de largo. C. tsudae tiene además conidios más pálidos (Deng et al, 2015).

\section{Curvularia brachyspora Boedijn (Fig.8)}

Colonias en papa zanahoria de crecimiento rápido, aterciopelada a flocosas, gris café a café negruzco. Estroma a veces presente, negro, cilíndrico, dispuesto en pequeños grupos. Conidióforos que nacen únicos o en grupos, en forma terminal o lateral desde las hifas o el estroma, derechos o flexuosos, pálidos hacia el ápice, hasta $700 \mu \mathrm{m}$ de largo. Conidios usualmente levemente curvos, elipsoidales a ampliamente fusiformes, 20-26 x 10-14 $\mu \mathrm{m}$, asimétricos, lisos, café oscuros, con 3 septos, el central verdaderamente meridional y más oscuro que los otros 2.

Distribución: pantropica.

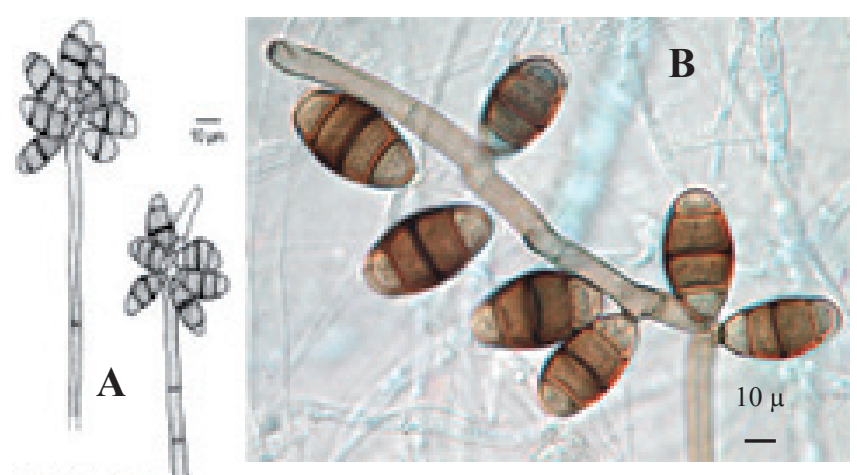

是是 Figuras 8. A-B.Curvularia brachispora, conidios y conidioforos $\theta \beta \theta$ (A.Tomado de: de Hoog et al,

7. Curvularia chlamydospora Madrid, Da Cunha, Gené \& Guarro.(Fig. 9)

Colonias en agar avena de $76 \mathrm{~mm}$ diámetro en 7 días a $25^{\circ} \mathrm{C}$, funiculosas, gris verdosas o verde oscuras, de margen fimbriado; reverso oliva gris a verde oscuro. Colonias en PCA de $68 \mathrm{~mm}$ diám. a la misma temperatura de incubación, funiculosas al centro, efusas hacia la periferia, verde oscuras con margen fimbriado y reverso verde oscuro. Hifas vegetativas septadas, ramificadas, subhialinas a café, lisas 1,5-4 $\mu \mathrm{m}$ de ancho, anastomosadas. Conidioforos semi a macronematosos, mononematosos, septados, usualmente únicos, geniculados o curvados en el ápice, café a café oscuro, lisos a asperulados, 22-323 x 2-5 $\mu \mathrm{m}$. Células conidiógenas terminales o intercalares, politréticas, que proliferan simpodialmente, subcilíndricas a formas irregulares, 7-18 x 5-10 $\mu \mathrm{m}$. Conidios con 4 celulas, mayormente levemente curvos, 16-25 x 7-12 $\mu \mathrm{m}$, en la parte más ancha, de pared lisa (célula basal verrugosa bajo SEM), usualmente con un septo central que aparece levemente marcado, la tercera célula desde la base es ligeramente grande y de lados no iguales, segunda y tercera célula más oscura que las otras, café a café oscuro, célula final pálida. Hilum no protuberante, plano, oscuro 


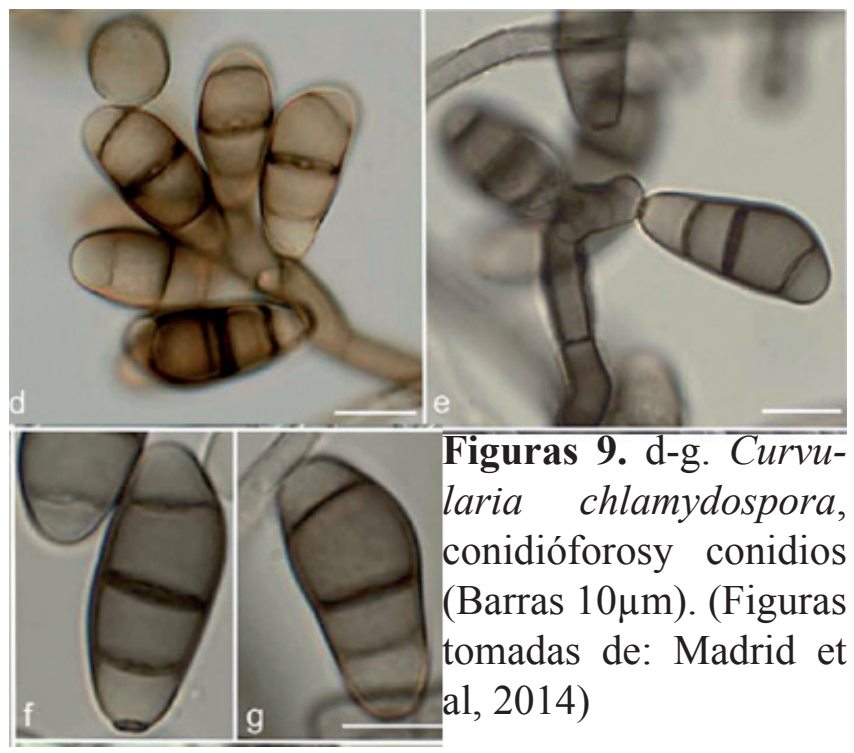

y de pared gruesa, 1,5-3 $\mu \mathrm{m}$ de ancho. Clamidosporas presentes, inicialmente como cadenas intercalares pero después formando racimos de células brotantes, 13-80 $\mu \mathrm{m}$, lisas a verrugosas y de paredes gruesas. Microconidiación presente, formando conidios de 1-2 células, café pálidos, globosos a subglobosos, 4-6 $\mu \mathrm{m}$ diám. Teleomorfo no observado. Distribución USA.

Nota. C. chlamydospora es superficialmente similar a las 3 especies que producen conidios con 4 células con un acentuado septo mediano, tales como: C. brachyspora, C. eragrostidis y C. intermedia, sin embargo, la tercera célula desde la base es usualmente grande y más pigmentada que la segunda en C. chlamydospora mientras en los 3 taxa similares ambas células intermedias son más bien iguales en tamaño y pigmentación. Estas especies no se han reportado en cuanto a la producción de clamidosporas en cultivos y tienen anchos conidios, por ej. 10-14 $\mu \mathrm{m}$ en C. brachyspora, 11-20 $\mu \mathrm{m}$ en $C$. eragrostidis y13-20 $\mu \mathrm{m}$ en $C$. intermedia (Sivanesan 1987). Curvularia eragrostidis y $C$. intermedia residen en el clado eragrostidis, mientras $C$. chlamydospora pertenece al clado lunata . C.brachyspora parece ser un taxón hermano de $C$. chlamydospora, pero esta relación recibe poco soporte estadístico (Vea, Madrid et al, 2014).
8. Curvularia clavata B.J. Jane (Fig. 10)

Colonias en agar papa zanahoria de crecimiento rápido, de color café grisáceo o café, algodonosas. Conidióforos derechos o flexuosos, a veces geniculados, café, de paredes lisas, hasta unos $150 \mu \mathrm{m}$ de largo y 2-5,5 $\mu \mathrm{m}$ de ancho, angostándose en la base y más gruesos hacia el ápice. Conidios café, de paredes lisas, derechos o ocasionalmente levemente curvos, usualmente clavados, con un hilum no protuberante o levemente protuberante, a veces truncado en la base, con 3 distoseptos café a negros, célula basal café pálida, otras células café a café oscuro 17-29 (23) x 7-13(9,6) $\mu \mathrm{m}$.

Común en: Sorghum, Oryza, Saccharum, Tripogon, Triticium, Zea.

Distribucion: pantrópica.

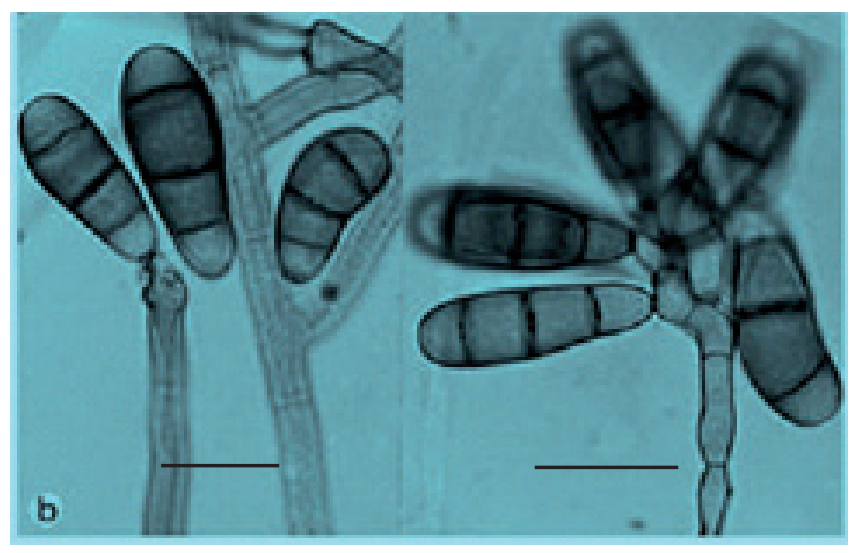

Figura 10. C.clavata, conidioforos y conidios (Figuras tomadas de: de Hoog et al, 2000. Barras $20 \mu \mathrm{m}$

9. Curvularia geniculata (Tracy \& Earle)Boedijn (Fig.11) $=$ Helminthosporium geniculatum Tracy \& Earle, Conidióforos hasta $600 \mu \mathrm{m}$ largo, 5-9 $\mu \mathrm{m}$ grosor, usualmente no ramificados, septados, café rojizos a rojo oscuro o café rojizo oscuro, pálidos cerca del ápice, derechos, flexuosos o geniculados cerca del ápice, con conspicuos y gruesas cicatrices conidiales. Conidios usualmente curvos, geniculados, fusiformes, 3-4 distoseptos, pero generalmente con 4 septos, raramente 5 , célula terminal, $26-48 \times 8-13 \mu \mathrm{m}$, en sustrato natural y en cultivo, 
18-37 x 8-14 $\mu \mathrm{m}$; la célula basal y apical son café pálidas, las células intermedias, café o café oscuro, lisas, (doblado como una rodilla), la célula central usualmente café oscuro y brotante, lisa, grande y más oscura que las otras células, cicatriz basal levemente protruyente.

La especie es heterotálica y el teleomorfo se obtiene por apareamiento de polos compatibles. Distribución: pantrópica.

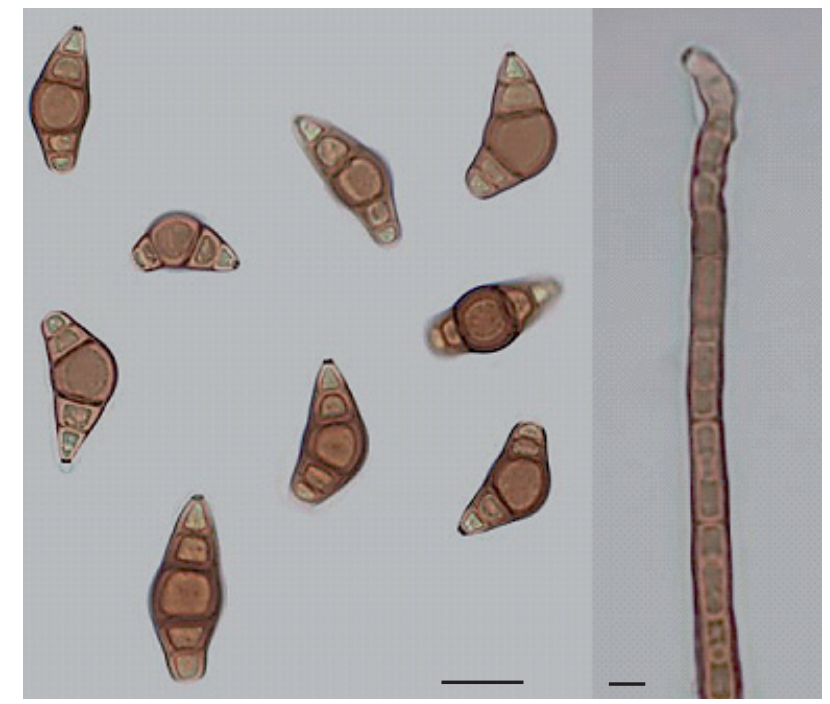

Figuras 11, C. geniculata conidios y conidióforo erecto Barras 20 y $5 \mu \mathrm{m}$ (Figuras tomadas de: E. McKenzie Landcare Research).

10. Curvularia hawaiiensis (Bugnic.) Manamgoda, L. Cai \& K.D. Hyde, comb. nov. (Fig. 12)

= Helminthosporium hawaiiensis Bugnic.,

= Drechslera hawaiiensis Bugnic. ex M.B. Ellis

= Bipolaris hawaiiensis (M.B. Ellis) J.Y. Uchida \& Aragaki, = Cochliobolus hawaiiensis Alcorn,

= Pseudocochliobolus hawaiiensis (Alcorn) Tsuda \& Ueyama.

Colonias en agar papa zanahoria, de rápido crecimiento, efusas, grises. Estroma a veces se forma en cultivo, erecto, derecho, más o menos cilíndrico, simple o ramificado, negro. Conidióforos únicos, flexuosos, geniculados, lisos, cilíndrico, enroscados, septados, pálidos a café mediano, hasta $120 \times 2-7 \mu \mathrm{m}$, nodos conidiógenos verrugosos. Conidios derechos, elipsoidales, oblongos o cilíndricos, redondeados en sus extremos, pálidos a café mediano, 2-7 distoseptos (mayormente 5), 12-37 x 5-11 $\mu \mathrm{m}$. Conidios que a menudo germinan por un tubo germinal por un extremo y un conidióforo por el otro extremo.

Es una especie heterotálica y el teleomorfo se obtiene por unión de polos compatibles. Distribución: cosmopolita, aislados desde una gran variedad de plantas, aire, suelo y en clínica (Minckler, et al, 2014).

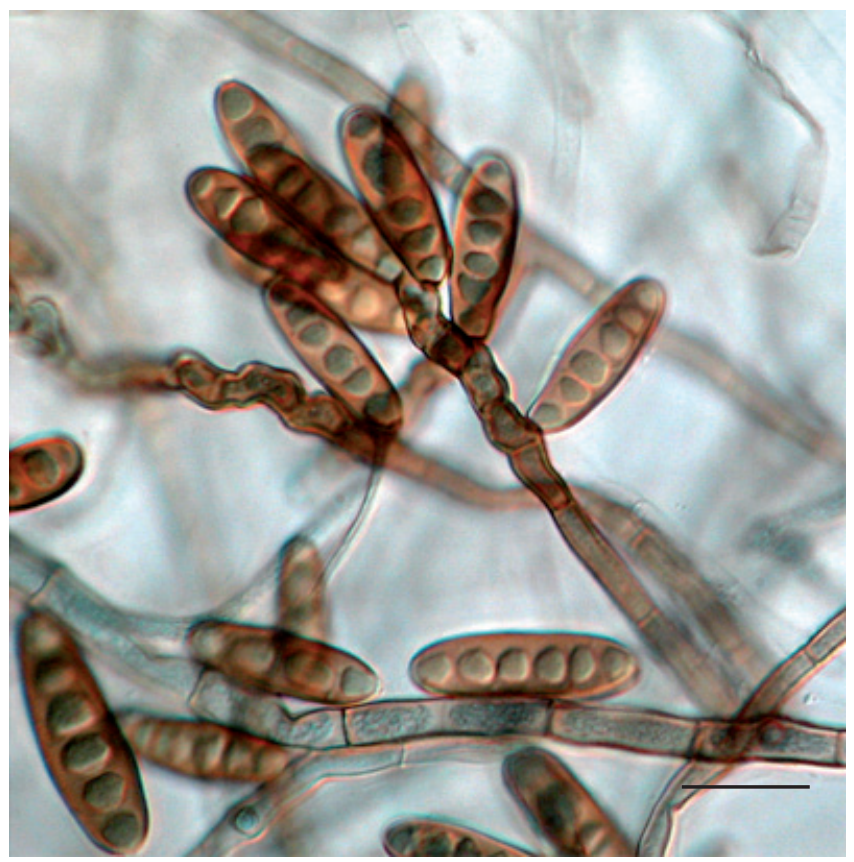

Figura 12. Curvularia hawaiensis, conidióforos y conidios (Barra $20 \mu \mathrm{m}$ ).

11. Curvularia hominis Da Cunha, Madrid, Gené \& Cano, sp. nov. (2014) (Fig.13)

Etimología. Hace referencia a que todos los aislados fueron aislados de especímenes clínicos humanos.

Colonias en agar papa zanahoria, aterciopeladas, con un diámetro de 70-72 $\mathrm{mm}$ en 7 días a $25^{\circ} \mathrm{C}$, funiculosas y verde oscuras en el centro, flocosas y de color oliva a blanco hacia la periferia, con un margen fimbriado y un reverso oliva a verde oscuro. Hifas vegetativas septadas, ramificadas, subhialinas a café, lisas a levemente asperuladas, 1,5 - $5 \mu \mathrm{m}$ de ancho, anastomosadas. Conidióforos semi a macronematosos, mononematosos, septados, simples o ramificados, geniculados hacia el ápice, 
subhialinos a café oscuros, lisos a asperulados, con paredes celulares a menudo más gruesas que las de las hifas vegetativas, $55-325$ x 2-5 $\mu \mathrm{m}$. Células conidiógenas terminales o intercalares, politréticas, que proliferan simpodialmente, subcilíndricas a tamaño irregular, 6-26 x 4-9 $\mu \mathrm{m}$; locus conidiógenos usualmente más o menos engrosados y oscuros. Conidios 4-5 celulas, levemente curvadas, 18-30 x 7-14 $\mu \mathrm{m}$ en la parte más ancha, con la tercera célula desde la base a menudo grande y de lados desiguales, células intermedias a menudo verrugosas y más oscuras que las otras, café, célula final subhialina a café pálido y de pared lisa; hilum no-protuberante, plano, oscuro y grueso, 1,5-3 $\mu \mathrm{m}$ de ancho. Microconidiación y clamidosporas no observadas. Teleomorfo no observado. Distribución USA.

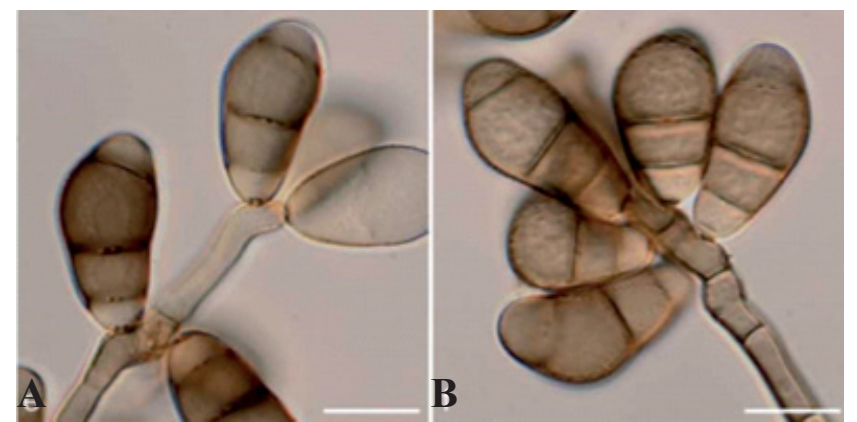

Figuras 13. A-B, Curvularia hominis, conidioforos y conidios mostrando leve rugosisdad superficial (Figuras tomadas de: Madrid et al, 2014. Barras $=10 \mu \mathrm{m}$ ).

Nota. A pesar que esta especie fue aislada de casos clínicos humanos, es también común en el ambiente. Curvularia hominis semeja otras especies del genero con 4 células por conidio y una brotación asimétrica, una oscura tercera célula, tal como $C$. aeria, $C$. caricapapayae, C. lunata y $C$. prasadii, pero difiere de éstas en producir conidios con células intermedias verrugosas (Fig.13 A-B). Las ultimas 4 especies son miembros del clado lunata, mientras $C$. hominis y C.muehlenbeckiae forman un distinto linaje, como el clado hominis (vea: Madrid et al, 2014).

12. Curvularia inaequalis (Shear) Boedijn (Fig. 14) =Helminthosporium inaequale Shear =Acrothecium arenarium Moreau \& V. Moreau
Colonias en PDA efusas, grises a negras, algodonosas a aterciopeladas, a menudo zonadas. Estroma ausente pero detectado por Shear en viejos cultivos. Conidióforos que nacen únicos o en grupos terminales y laterales en las hifas, únicos o ramificados, derechos o flexuosos, a menudo geniculados, café pálidos, a café, lisos, septados, hasta $250 \times 3-7 \mu \mathrm{m}$. Conidios derechos o levemente curvos, elipsoidales a ampliamente fusiformes, con un hilum escasamente protruyente y a menudo truncado, 2-6 distoseptos, pero predominantemente 4, la célula central usualmente más grande que las otras células, los 2 septos a cada extremo a menudo bastante cercanos uno a otro, a veces con todas las células café o café oscuro, pero frecuentemente con una o ambas células finales a veces más pálidas que las otras, lisas 24-45 $(32)$ x 9-16 $(12,4) \mu \mathrm{m}$ en la parte más ancha.

Distribución: aparentemente cosmopolita.

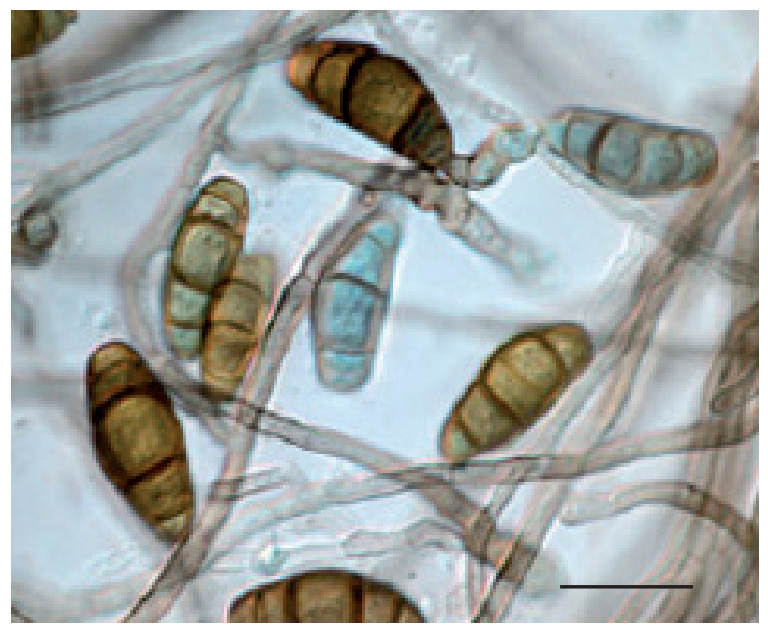

Figura 14. Curvularia inaequelis, Conidióforos y conidios. Barra $20 \mu \mathrm{m}$.

13. Curvularia lunata (Wakker) Boedijn(Fig.15)

= Acrothecium lunatum Wakker,

$=$ Cochliobolus lunatus R.R. Nelson \& F.A. Haasis,

=Pseudocochliobolus lunatus (R.R. Nelson \&

F.A.Haasis) Tsuda, Ueyama \& Nishih

=Helminthosporium caryopsidum Sacc.

= Curvularia caryopsidum (Sacc.) S.C Teng.

Colonias en CMA con un diámetro de 7,2 $\mathrm{cm}$ en 7 dias a $27^{\circ} \mathrm{C}$, funiculosas a algodonosas, 
oliváceas a negras, con márgen fimbriado; reverso negro. Colonias en MEA con un diámetro de $70 \mathrm{~mm}$ a la misma temperatura y tiempo de incubación, algodonosas y grises en el centro, canela y aterciopeladas hacia la periferia, con margen fimbriado; reverso café al centro y de color crema hacia la periferia. Hifas vegetativas, septadas, ramificadas, subhialinas a café, lisas a asperuladas, 15-5 $\mu \mathrm{m}$ de ancho, anastomosadas. Conidióforos semimacronematosos a macronematosos, mononematosos, septados, simples o ramificados, a menudo con base bulbosa, geniculada o torcida en el ápice, blanca a café oscuro, lisas a asperuladas con pared celular a menudo más gruesa que las hifas vegetativas $39-430$ x $4-9 \mu \mathrm{m}$, en la base y $2,5-6 \mu \mathrm{m}$ hacia el centro. Células conidiógenas terminales e intercalares, politréticas, subcilíndricas, clavadas y subglobosas de tamaño irregular, $4-20 \times 3-13 \mu \mathrm{m}$, que proliferan simpodialmente. Locus conidiógenos algo engrosados y oscuros, poros hasta $1 \mu \mathrm{m}$ ancho. Conidios mayormente con 4 células, lisos a asperulados, a menudo curvos en la tercera célula desde la base, la cual es larga como las otras células intermediarias, café o café oscuras y célula terminal subhialina a café claro, 21-31x 9-13 $\mu \mathrm{m}$; hilum no protruyente, plano, oscuro y engrosado,

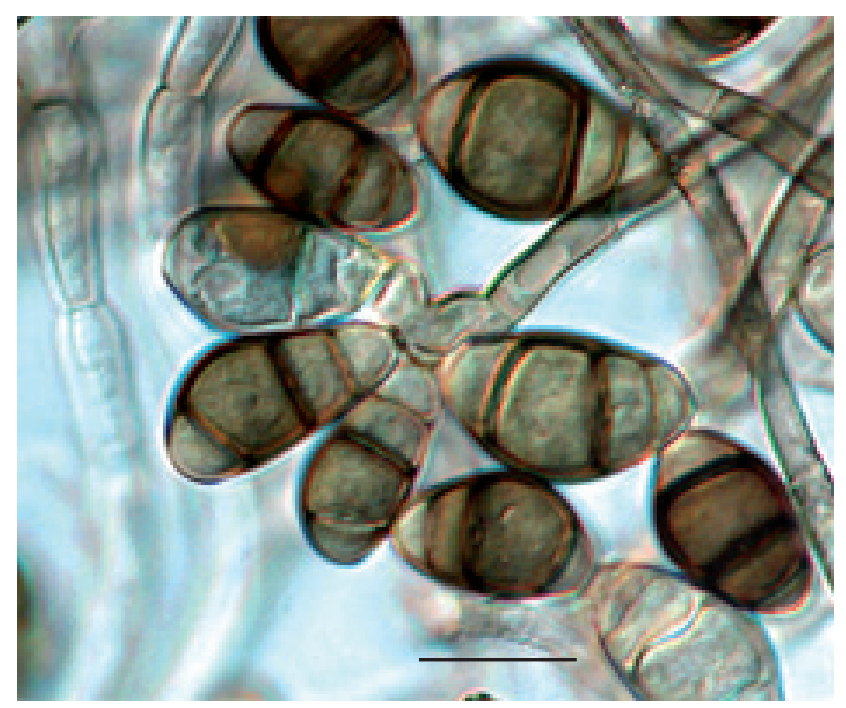

Figura 15. Curvularia lunata. Conidióforos y conidios. Barra $20 \mu \mathrm{m}$.

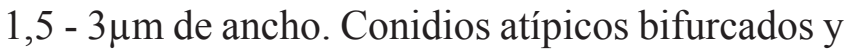
conidiación microcíclica raramente observada.

Nota. C. lunata fue descrita primeramente como Acrothecium lunatum desde hojas caídas de caña de azúcar en Java (Wakker \& Went, 1899). Boedijin (1933), transfirió esta especie al género Curvularia y la nombró la especie tipo, citando nuevos aislamientos desde el aire, el mango y otros sustratos. Los aislados existentes hacen posible confirmar que es una especie criptica (Manamgoda et al, 2012). Distribución cosmopolita.

\section{Curvularia pallescens Boedijn (Fig. 16)}

$=$ Cochliobolus pallescens (Tsuda \& Ueyama) Sivan. $=$ Pseudocochliobolus pallescens Tsuda \& Ueyama.

Característica de las colonias en agar papa zanahoria: de crecimiento rápido, lanosas en el centro, a menudo con desarrollo de zonas concéntricas. Conidióforos simples, raramente ramificados, derecho o a veces geniculados cerca del ápice, de color café, variables en largo, hasta 5-6 $\mu \mathrm{m}$ de ancho. Conidios de paredes lisas, café pálidos o con poco color, mayormente con 3 septos, elipsoidales a fusiformes, usualmente levemente curvos, 17-32 x 7-12,5 $\mu \mathrm{m}$, a menudo desproporcionalmente agrandados en la tercera célula y marcadamente geniculados o en forma de gancho. Conidios escasos en cultivos, variables en tamaño y forma según los aislados. Distribución: cosmopolita. La especie es heterotálica y el teleomorfo se obtiene por apareamiento de polos compatibles.
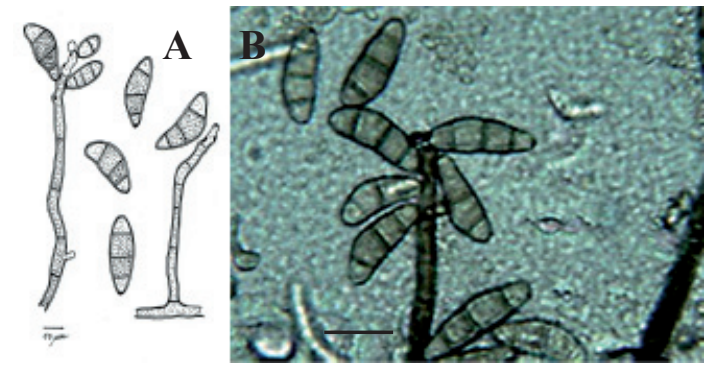

Figuras 16. A-B, Curvularia pallescens, A. Conidióforos y conidios (Tomado de: www.plantasyhongos.es), B. Conidióforo y conidios (Tomado de: micologiapanama. blogspot. com, Barra $20 \mu \mathrm{m}$ ) 
15. Curvularia papendorfii (van der Aa) Alcorn (Fig. 17)

=Drechslera papendorfii (Aa) M.B. Ellis

=Bipolaris papendorfii (Aa) Alcorn,

$=$ Curvularia siddiquii S.I. Ahmed \& M. Qureshi

Características de las colonias en papa zanahoria: efusas, aterciopeladas grises a negras. Conidióforos solitarios, derechos o flexuosos, geniculados, pálidos a café mediano, hasta $200 \mu \mathrm{m}$ largo, 4-9 $\mu \mathrm{m}$ de ancho, de paredes lisas, septados, con una prominente cicatriz oscura. Nodos conidiógenos verrugosos, distintamente brotantes hasta $5 \mu \mathrm{m}$ ancho. Conidios curvados, en forma de riñón u obpiriformes, usualmente anchos en la segunda célula desde la base, café mediano a café oliváceo oscuro, pálidos en los extremos, lisos, con 3 distoseptos, 30-40 x 15-20 $\mu \mathrm{m}$. Esta especie es fitopatógena y raramente causa infecciones oportunistas. Sus metabolitos secundarios poseen propiedades medicinales y anticáncer (Kuan et al,2015). Distribución aparentemente cosmopolita.

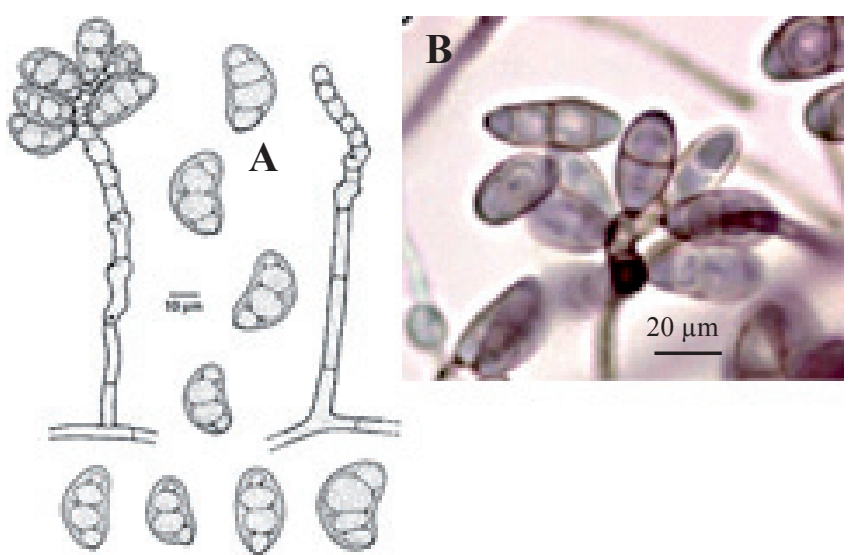

Figuras 17. A-B. Curvularia papendorfii, conidióforos y conidios (Tomado de: de Hoog et al, 2000; B. Tomada de: Kuan et al, 2015)

17.Curvularia pseudolunata Da Cunha, Madrid \& Gené, sp. nov. (Madrid et al, 2014) (Fig. 19)

Colonias en agar avena con un diámetro de $71 \mathrm{~mm}$ en 7 días a $25^{\circ} \mathrm{C}$, algodonosa a lanosa, gris verdosa, con un margen fimbriado y un reverso verde oscuro. Colonias en PCA, 78 mm diámetro a la misma temperatura y tiempo de incubación, lanosa en el centro, flocosa hacia la periferia, verde grisácea con margen fimbriado; reverso oliva verde. Hifas vegetativas septadas, ramificadas, subhialinas a café, lisas, 1,5-5 $\mu \mathrm{m}$ de ancho. Conidióforos macronematosos, mononematosos, septados, no ramificados, geniculados cerca del ápice, café, lisos, 100-350 x 2-4,5 $\mu \mathrm{m}$. Células conidiógenas mayormente terminales, politréticas, que proliferan simpodialmente, subcilíndricas, subglobosas a formas irregulares, 4,5-30 x 6-10 $\mu \mathrm{m}$. Conidios 4 células, mayormente curvados, 20-27 x 8-12 $\mu \mathrm{m}$, con la tercera célula desde la base usualmente de tamaños desiguales, grande y oscura más que las otras, café. La segunda y la célula final subhialinas a café pálido, lisas, célula basal a menudo verrugosa; hilum no protruyente, plano, oscuro y engrosado, 1,5-2,5 $\mu \mathrm{m}$ de ancho. Clamidosporas abundantes, inicialmente como cadenas intercalares, posteriormente formando racimos de células brotantes, hasta de $60 \mu \mathrm{m}$ diámetro, lisas y de paredes gruesas. Microconidiación ausente. Teleomorfo no observado. Distribución USA, Europa.

Nota. Curvularia pseudolunata es morfológicamente similar a $C$. lunata y este taxón se agrupa junto en los 4 locus de la filogenia. Sin embargo, los conidios de $C$. lunata son levemente más largos (21-31 x 9-13 $\mu \mathrm{m})$ y esta especie se separa de C. pseudolunata por una distancia genética considerable (Madrid et al, 2014).

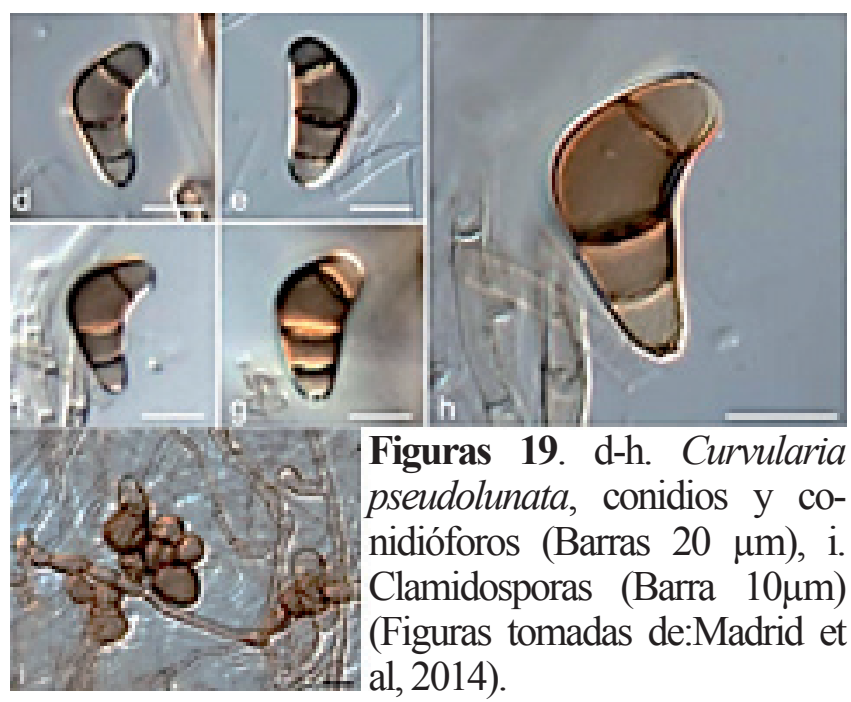


18. Curvularia senegalensis (Speg.) Subram. =Brachysporium senegalense Speg. (Fig. 20)

Colonias en agar papa zanahoria (APZ), de rápida dispersión, efusas, aterciopeladas, negras oscuras a café negras. Conidióforos simples o ramificados o en grupos terminales y laterales en las hifas, derechos o flexuosos, a veces geniculados, cafesosos, de paredes lisas, hasta 150 × 3-7 $\mu \mathrm{m}$. Conidios usualmente curvos, de lados no iguales, lisos, café oscuros, las células de los extremos usualmente subhialinas o café pálidas, usualmente curvas, con 3-5 seudoseptos (mayormente 19- 30 (24 prom.) x 10-14 $(11,4) \mu \mathrm{m}$, en la parte más ancha. C. geniculata, tiene también conidios con 4 septos, pero es marcadamente geniculada y brotante, con una célula central usualmente muy diferente a las restantes. Distribución: en gramíneas en zonas tropicales y subtropicales (especie rara).

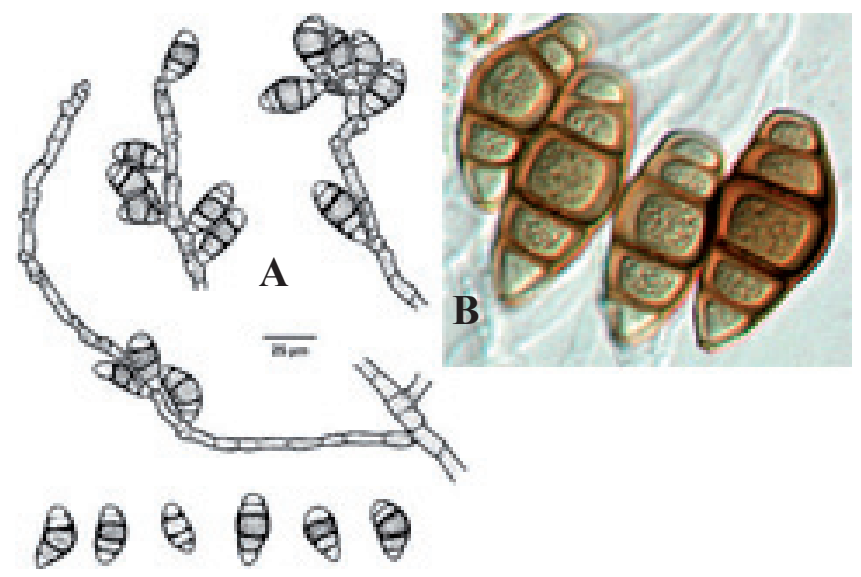

Figuras 20. A-B. Curvularia senegalensis, A. Conidios y conidióforos, B. Conidios (A. Tomado de: Guarro et al, 1999)

19. Curvularia spicifera (Bainier) Boedijn (Fig. 2 y 21$)$

= Helminthosporium spiciferum (Bainier) Nicot,

= Bipolaris spicifera (Bainier) Subram.,

= Dendryphion spiciferum (Bainier) Sacc. \& Traverso

=Pseudocochliobolus spicifer (R.R. Nelson) Tsuda, Ueyama\&Nishih.

= Helminthosporium tetramera

= Curvularia tetramera (McKinney) Boedijn ex J.C. Gilman,

= Bipolaris tetramera (McKinney) Shoemaker,
= Drechslera tetramera (McKinney) Subram. \& B.L. Jain,

Colonias en agar papa zanahoria que se expanden, rápidamente, de aspecto vidrioso, recubierto con conidios puntiformes o peluda si la esporulación es pobre. Óptimo crecimiento se observa en agar avena a $32^{\circ} \mathrm{C}$, lento crecimiento a18 y $37^{\circ} \mathrm{C}$. Conidióforos erectos, no ramificados, solitarios o en pequeños grupos, septados, repetidamente geniculados, con numerosas cicatrices bien definidas, a menudo torcidos, hasta $300 \times 4-8 \mu \mathrm{m}$, regularmente zigzagueantes en la parte apical, con cicatrices planas, café oscuras en la punta. Nodos conidiógenos verrugosos. Conidios de color café mediano, excepto por lo angosto y el subhialino lunar en las extremidades, cilíndricos con extremos redondeados, 20-40 x 9-14 $\mu \mathrm{m}$, con 3 distoseptos. Hilum de 2-3 $\mu \mathrm{m}$ de ancho, Conidios que germinan por un tubo germinal en un extremo y un conidióforo por el otro extremo o solamente desde la célula basal.

Especie heterotálica: el telomorfo se obtiene apareando conidios de distinta polaridad.

Distribución: cosmopolita.

Nota. Se diferencia de C.australiensis por su conidios más anchos. Especie común como saprófito en material vegetal diverso y el suelo; frecuentemente se encuentra como agente de sinusitis humana o animal (Buzina et al, 2003)

A

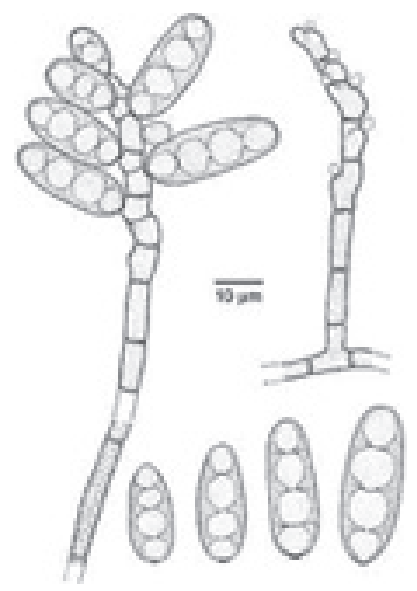

Figura 21. A. Curvularia spicifera, conidióforos y conidios (A. Tomada de: de Hoog et al , 2000) 
20. Curvularia verruculosa Tandon \& Bilgrami (Fig.22) = Curvularia verruculosa Tandon \& Bilgrami ex M.B. Ellis,

Colonias en papa zanahoria de crecimiento rápido, de color café, lanosa o aterciopelada, reverso café oscuro a negro. Conidióforos simples, raramente ramificados a veces geniculados cerca del ápice, café a café oscuros, variables en largo, hasta 5-6 $\mu \mathrm{m}$ de ancho. Conidios café, elipsoidales a clavados, derechos o curvos, a menudo de lados desiguales, célula mediana café, a veces la segunda célula desde la base es similar en color a la tercera, las células basales y apicales de color café claro, normalmente con 3 distoseptos, distintamente verrugosa, especialmente en las 2 centrales. En sustratos naturales los conidios miden 2532 (29) x 12-14 (13.3) $\mu \mathrm{m}$, en cultivo 20-40 x 12-17 (14) $\mu \mathrm{m}$. Común en hojas de. Oryza sativa. Distribución cosmopolita. La especie es cercana a Curvularia trifolii (Kauff.) Boed., pero difiere en la naturaleza verrugosa de la pared conidial y en la ausencia del marcado hilum protuberante presente en C. trifolii.

Notas. Curvularia muehlenbeckiae Madrid, Da Cunha, Gené, Guarro \& Crous, sp. nov (2014), es un taxón hermano de $C$. hominis, el cual tiene conidios un poco mas grandes (18-30 x 7-14 $\mu \mathrm{m})$ con similares ornamentaciones que consisten en pequeñas y conspicuas verrugas. Algunas especies de Curvularia, fuera del clado hominis, producen conidios verrugosos, ej, C. tuberculata, C. verruculosa y $C$. verruciformis. las primeras 2 especies producen grandes conidios ( 23-52 x 13$20 \mu \mathrm{m}$ (con 3-5 septos o más) y 20-40 x 12-17 $\mu \mathrm{m}$, respectivamente), mientras la tercera, difiere de los miembros del clado hominis por tener mayoritariamente 5 células conidiales mas fuertemente ornamentadas (Ellis 1966, Sivanesan 1987). Las especies de Curvularia con conidios verrugosos aparecen en diferentes clados lo que sugiere que este tipo de ornamentación ha evolucionado varias veces en el género( Madrid et al,2014).

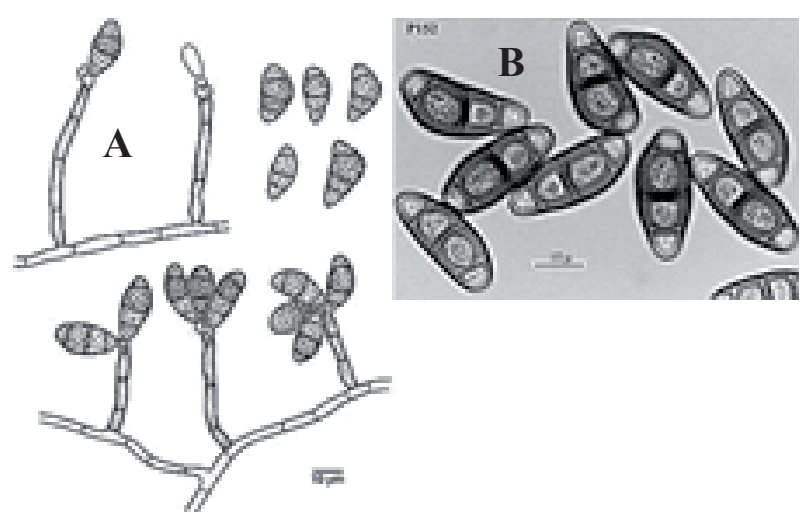

Figuras 22. A-B. C. verruculosa. A. Conidios y conidióforos (Tomado de: de Hoog et al, 2000), B. Conidios mostrando su rugosidad ( Tomado de: Matsuchima 1971).

\section{Clave tentativa dicotómica/politómica para las especies más comunes de Curvularia en clínica (Modificada de Sivanesan, 1987)}

1. - Conidios verugosos o levemente asperu lados, mayormente con 3 distoseptos........2 - Conidios lisos con 3 distoseptos.............. 4

- Conidios lisos con 4 distoseptos............... 8

- Conidios lisos con hasta 7 distoseptos ...9

2. - Clamidosporas presentes, conidios con 3 septos, levemente verrugosos en la célula basal, 16- 25 x 7-12 $\mu \mathrm{m}$, microconidiación presente C. chlamydospora

-Clamidosporas ausentes...............................3

3. - Conidios verrugosos, mayormente 3 septos 20- $40 \times 12-17 \mu \mathrm{m}$

C. verruculosa

- Conidios levemente verrugosos en la cé lula basal, con 3 septos, microconidiación a veces presente, $13-28 \times 7-15 \mu \mathrm{m}$

C. americana

- Conidios levemente verrugosos principalmente en las células intermedias, con 3

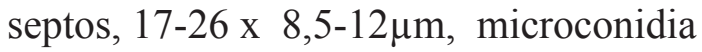
ción ausente vea C.muehlenbekiae

(no incluida en el texto, vea Madrid et al. 2014) 
- Conidios levemente verrugosos, principalmente en las células intermedias, con 3 septos, 18-30 x7- $14 \mu \mathrm{m}$, microconidiación ausente C. hominis - Conidios con célula basal a menudo ve rrugosa, con 3 septos, mayormente curvos, con la tercera célula desde la base más grande, $20-27 \times 8-12 \mu \mathrm{m}$,

C.pseudolunata

- Conidios lisos o asperulados, con 3 septos, a menudo curvos en la tercera célula desde la base (que es más grande), células intermedias café y las finales más claras, 21-31 x 9-13 $\mu \mathrm{m}$ C. lunata

4. - Conidios mayormente 3 pseudoseptos, derechos o curvos. .5 - Conidios mayormente de 4 pseudoseptos

5. - Conidios con 3 seudoseptos, mayormente derechos, clavados, célula basal palida, $17-29 \times 7-13 \mu \mathrm{m}$

C.clavata

- Conidios siempre con 3 seudoseptos, derechos, usualmente no más de $11 \mu \mathrm{m}$ de an cho, $14-40$ × 9-11 $\mu \mathrm{m}$

\section{C. australiensis}

- Conidios siempre con 3 seudoseptos, cilín dricos u oblongos, usualmente mayores que $11 \mu \mathrm{m}$ de ancho, 20-40 x 9-14 $\mu \mathrm{m}$

C. spicifera

- Conidios usualmente levemente curvos a curvos ...6

6. - Conidios con septo mediano oscuro y grueso. C.brachyspora
- Conidios sin septo mediano grueso y os-

curo.

7. - Conidios café pálidos, elipsoidales a fusiformes, levemente curvos, 17-32 x 7-12 $\mu \mathrm{m}$.

C.pallescens

- Conidios, lisos típicamente curvos, en forma de riñon u obpiriformes, usualmente anchos en la segunda célula desde la base, $30-40 \times 15-20 \mu \mathrm{m}$.

C.papendorfii

8. - Conidios café oscuros, con 4 septos, distintamente geniculados, con célula central dilatada, $18-37$ x 8-14 $\mu \mathrm{m}$.

C.geniculata

- Conidios café oscuros, con 4 septos, no distintamente geniculados, con las células terminales pálidas, 19-20 x 10- $14 \mu \mathrm{m}$.

C. senegalensis

9. -Conidios con hasta 6 distoseptos, la célula central más grande que las otras, 25 x 45 x $9-16 \mu \mathrm{m}$ C.inaequalis - Conidios con 2-7 septos (mayormente 5), derechos elipsoidales o cilíndricos, redondeados en sus extremos,12-37 x 5-11

C.hawaiiensis

La clave es solo orientativa, la similitud de algunas especies dificulta su diferenciación y debe compararse con las descripciones originales en la literatura. Actualmente es necesario el empleo secundario de la biología molecular para la real confirmación final del aislado. No debe olvidarse, que antes de una determinación definitiva el tratamiento del paciente es primordial y debe valorarse con premura la sensibilidad del aislado frente a los antifúngicos modernos. 


\section{REFERENCIAS}

Adam, R.D. et al. (1986). Phaeohyphomycosis caused by the fungal genera Bipolaris and Exserohylum. Medicine 65: 203-217

Alcorn, J.L. (1988). The taxonomy of 'Helminthosporium' species. Annual Review of Phytopathology 26: 37-56.

Barr, M.E. (1979). A classification of Loculoascomycetes. Mycologia 71:935-957

Berbee, M.L.; Pirseyedi, M. \& Hubbard, S. (1999). Cochliobolus phylogenetics and the origin of known, highly virulent pathogens inferred from ITS and glyceraldehyde-3-phosphate dehydrogenase gene sequences. Mycologia 91:964-977

Boedijn, K.B. (1933). Über einige phragmosporen Dematiazen. Bulletin du Jardin Botanique de Buitenzorg 13:120-134

Buzina,W.; Hannes Braun.; Kerstin, Schimpl, \& Heinz, Stammberger. (2003). Bipolaris spicifera Causes Fungus Balls of the Sinuses and Triggers Polypoid Chronic Rhinosinusitis in an Immunocompetent Patient. J Clin Microbiol. 2003 Oct; 41:4885-4887

Carlson, H.; Nilsson, P.; Jansson, H.B. \& Odham, G. (1991). Characterizationand determination of prehelminthosporol, a toxin from the plant pathogenic fungus Bipolaris sorokiniana, using liquid chromatography/mass spectrometry. J. Microbial Meth. 13: 259-269

Castelnuovo, et al. 2004. Invasive fungal sinusitis due to Bipolaris hawaiiensis. Mycoses 47:76-81

Chowdhary, A.; Randhawa, H.S.; Singh, V. et al, (2011).Bipolaris hawaiiensis as etiologic agent of allergic bronchopulmonary mycosis: first case in a pediatric patient. Medical Mycology 49: 760-765 da Cunha,K.C., Sutton,D.A.; Fothergoll, A.W.; Cano, J. et al. (2012). Diversity of Bipolaris species in clinical samples in the USA and their antifungal susceptibility profiles. J. Clin. Microbiol. doi:10.1128/JCM.01965-12

da Cunha, K.C., Sutton, D.A., Fothergill, A.W., Gené, J., et al, (2013). In vitro antifungal susceptibility and molecular identity of 99 clinical isolates of the opportunistic fungal genus Curvularia. Diagnostic Microbiology and Infectious Disease 76: $168-174$

da Cunha, K.C. (2014). Phenotypic and Molecular Characterization of Clinical Isolates of Bipolaris, Curvularia, Exserohilum and Pithomyces, Tesis Doctoral.Facultat de Medicina i Ciències de la Salut Departament de Ciències Mèdiques Bàsiques, Reus.España.

Datnoff, L.E., \& Rutherford, B.A. (2004). Accumulation of silicon by Bermuda grass to enhance disease suppression of leaf spot and melting out. USGA Turfgrass and Environmental Research Online 2(18):1-6

Deng,H.; Tan, Y.P.; Shivas,R. \& Niu,Y.C. (2015). Curvularia tsudae comb. nov. et nom. nov., formarly Pseudocochliobolus australiensis, and revised synonymy for Curvularia australiensis. Mycoscience 56:24-28

Dennis, R.W.G. (1978). British Ascomycetes. Germany, J.Cramer.

Domsch, K.H. et al., (2007). Compendium of Soil Fungi. London: Academic Press.

Ebner, M. R., K. Haselwandter, and A. Frank. (1989). Seasonal fluctuations of airborne fungal allergens. Mycol. Res. 92:170-176 
Especies oportunistas de importancia clínica de los géneros Bipolaris Shoemaker y Curvularia Boedijn - E. Piontelli.

El Khizzi, N.; Bakheshwain, S. \& Parvez, S. (2010). Bipolaris: A Plant Pathogen Causing Human Infections: An Emerging Problem in Saudi Arabia. Research Journal of Microbiology 5:212-217

Ellis, M.B. (1966). Dematiaceous Hyphomycetes VII: Curvularia, Brachysporium,etc. Mycological Papers 106:1-57

Ellis, M.B. (1971). Hyphomycetes. Kew, England: Commonw. Mycol. Inst.

Ellis, M. B. (1976). More Dematiaceous Hyphomycetes. Kew, England: Commonw. Mycol. Inst.

Emami. K. \& Hack, E. (2002) Conservation of XYN11A and XYN11B xylanase genes in Bipolaris sorghicola, Cochliobolus sativus, Cochliobolus heterostrophus, and Cochliobolus spicifer. Curr. Microbiol 45:303-306

Farr, D.F. \& Rossman. A.Y. (2013). Fungal databases, systematic mycology and microbiology laboratory.http://nt.arsgrin.gov/fungaldatabases.

Franco, N.F. \& Zavaleta, N.E. (2001). Estado actual del conocimiento acerca del modo de acción de las toxinas no selectivas. Rev. Mex. Fitopat. 19:237-244

Gomes M, M.V.; Germani, J.C.\& Van Der Sand, S.T. (2005). The use of RAPD to characterize Bipolaris sorokiniana isolates. Genet. Mol. Res. 4:642-65

Goh, T-K.; Kevin, D. Hyde, D.K, \& Lee.L.K.D (1998). Generic distinction in the Helminthosporium-complex based on restriction analysis of the nuclear ribosomal RNA gene. Fungal Diversity 1:85-107.

Goodman, R.N.; Király, Z. \& Wood, K.R. (1986). The biochemistry and physiology of plant disease. Univ.Missuri, Press Columbia. USA.
Guarro, J. et al, (1999).Mycotic Keratitis due to Curvularia senegalensis and In Vitro Antifungal Susceptibilities of Curvularia spp. J.Clin. Microbiol. 37:4170-4173

Hagan, A. (2005). Leaf spot and rust diseases of turf grasses. Alabama Cooperative Extension System. http://www.aces.edu/pubs/docs/A/ANR0621/ANR-0621.pdf.

Jeon, J.S.;Thuong, T.T.m \& Lee, H.B. (2015). Phylogenetic Status of an Unrecorded Species of Curvularia, C. spicifera, Based on Current Classification System of Curvularia and Bipolaris Group Using Multi Loci. Mycobiology. 2015 43:210-217

Kirk,P.; Cannon, P.; Stalpers,J. \& Minter, D. (2008). Dictionary of the fungy CABI, UK.

Kobayashi H, et al. (2008). Disseminated infection by Bipolaris spicifera in an immunocompetent subject. Med. Mycol. 346:361-365.

Kodsueb, R.; Dhanasekaran, V.; Aptroot, A. et al. (2006). The family Pleosporaceae: intergeneric relationships and phylogenetic perspectives based on sequence analyses of partial 28S rDNA. Mycologia 98:571-583

Krizsán,K. (2012). Characterization of opportunistic pathogenic isolates of Cochliobolus. Ph.D.University of Szeged Faculty of Science and Informatics Department of Microbiology,Szeged.

Kuan, S.C et al, (2015).Dissecting the fungal biology of Bipolaris papendorfii: from phylogenetic to comparative genomic analysis. DNA Research, 22:219-232

Hoog GS de, Guarro J, Gené J, Figueras MJ (eds) (2000-2011). Atlas of Clinical Fungi,and CD-ROM version 
Especies oportunistas de importancia clínica de los géneros Bipolaris Shoemaker y Curvularia Boedijn - E. Piontelli.

Huenselback, J.P. \& Ronquist, F. (2001). MrBayes:Bayesian inferenceof phylogenetic trees. Bioinformatics 17:754-755

Luttrell, E. S. (1963) . Taxonomic criteria in Helminthosporium. Mycologia 55:643-74

Luttrell, E. S. (1964). Systematics of Helminthosporium and related genera. Mycologia 56:119-132 Madrid, H.; Da Cunha K.C.; Gene, J. et al, (2014). Novel Curvularia species from clinical specimens. Persoonia 33:48-60

Manamgoda, D.S.; Cai, L.; Bahkali ,A.H.; Chukeatirote, E.; Hyde KD. (2011).Cochliobolus: an overview and current status of species. Fungal Diversity 51:3-42

Manamgoda,S.D. et al., (2012).A phylogenetic and taxonomic re-evaluation of the Bipolaris - Cochliobolus Curvularia Complex Fungal Diversity 56:131-144

Magnamoda,D.SD.; Rossman, A.Y; Castlebury, L.A.; Madrid, H. et al, (2014). The genus Bipolaris. Studies in Mycology 79:221-288

Magnamoda,D.SD.; Rossman, A.Y; Castlebury, L.A, et al, (2015). A taxonomic and phylogenetic re-appraisal of the genus Curvularia (Pleosporaceae):human and plant pathogen. Phytotaxa 212:173-198

Marcus, L.; H. F.; Vismer, H. J.; van der Hoven, E.; Gove, P. (1992). Meewes Mycotic keratitis caused by Curvularia brachyspora (Boedjin). Mycopathologia119:29-33

Mathur, R.L. \& Mathur, B.L. (1959). A new species of Curvularia from the leaves of Jasminum sambac. Current Science 28: 448-449.

Matsushima, T. (1971). Microfungi of the Solomon Islands and Papua-New Guinea. :1-78
McGinnis, M. R.; Rinaldi, M. G. \& Winn, R. E. (1986). Emerging agents of phaeohyphomycosis: pathogenic species of Bipolaris and Exserohilum. J. Clin. Microbiol. 24:250-59

Mena, Portales J. (2004). Taxonomía del complejo Bipolaris, Curvularia, Drechslera y Exserohilum en Cuba. Tesis Doctoral. Inst. Ecol.y Sistem. Ministerio de Ciencia Tecnología y Medio Ambiente. Cuba.

Minckler, Don.; Small, K. W.; Wash, J.T. (2014).Clinical and Pathologic Features of Bipolaris Endophthalmitis After Intravitreal Triamcinolone. JAMA Ophthalmol.132:630-632(Bipolaris hawaiiensis)

Nalin, N. et al,(2014). Naming and outline of Dothideomycetes-2014 including proposal for the protection or suppession of generic names. Fungal Diversity $69: 1-55$

Olivier, C.; Berbee, M.L.; Shoemaker, R.A. \& Loria, R. (2000). Molecular phylogenetic support from ribosomal DNA sequences for origin of Helminthosporium from Leptosphaeria-like loculoascomycete ancestors. Mycologia 92:736-46

Picco, A. M.; Piontelli, E.; Rodolfi, M.; Vivar, V. (1999).Some species of Bipolaris and Curvularia protuberata in wild gramineae from northern Italy (Lombardia). Boletín Micológico14: 91-100

Pimentel,D.J. et al,(2005).Peritonitis Due to Curvularia inaequalis in an Elderly Patient Undergoing Peritoneal Dialysis and a Review of Six Cases of Peritonitis Associated with Other Curvularia spp. J. Clin. Microbiol. 43:8 4288-4292

Piontelli,E. \& Grizzoli, M.A. (1994). Especies graminícolas de Bipolaris, Drechslera y Curvularia en la $\mathrm{V}$ región (Chile): aspectos morfológicos y biogeográficos. Boletín Micológico 9:87-97 
Revankar, G.S. \& Sutton, A.D. (2010) Melanized Fungi in Human Diseas Clin.Microbiol. Review 23:884-928

Rong, I. H. (2001). An integrated approach to the taxonomy of some mitosporic fungi of the Bipolaris complex. Thesis for the degree of Philosophiae Doctor (Botany). Faculty of Natural and Agricultural Sciences.University of Pretoria

Rossman, M.K. \& S.L. Flory. (2012).Bipolaris microstegii sp. nov. Fungal Planet 129-20 D

Rossman, A Y.; Manamgoda, Dimuthu S.; Hyde, Kevin D. (2013). Proposal to conserve the name Helminthosporium maydis Y. Nisik. \& C. Miyake (Bipolaris maydis) against H.maydis Brond.and Ophiobolus heterostrophus (Ascomycota: Pleosporales: Pleosporaceae).Taxon, 62:1332-1333

Schell, W.A. (2000). Unusual fungal pathogens in fungal rhinosinusitis. Otolaryngol. Clin. N. Amer. 33:367-373

Schoch,C.L.; Crous, P.W.;Groenewald, J.Z. et al., (2009) A class-wide phylogenetic assessment of Dothideomycetes Stud. Mycol.64:1-15

Schubert, M. S. (2001). Fungal rhinosinusitis: diagnosis and therapy. Curr. Allergy Asthma Rep. 1:268-276.

Seifert, K.; Gareth, Morgan-Jones.; Walter, Gams. \& Bryce, Kendrick. (2011). The Genera of Hyphomycetes CBS, Netherland

Shimizu, K.; Chihiro, Tanaka. \& Mitsuya, Tsuda. (1998). Cloning of Brn1, a reductase gene involved in melanin biosynthesis in Cochliobolus heterostrophus. The Journal of General and Applied Microbiology 43:145-150

Sivanesan, A. (1984). The bitunicate Ascomycetes an their anamorphs. Germany: Straus \& Cramer
Sivanesan, A. (1987). Graminicolous species of Bipolaris. Curvularia, Drechslera, Exserohilum and their teleomorphs. CAB Internat. Mycol. Inst. Mycol. Pap. No. 158

Sivanesan, A. (1992). New Bipolaris, Curvularia and Exserohilum species Mycological Research 96:485-489

Shoemaker, R.A. (2006). Nomenclature of Drechslera and Bipolaris, grass parasites segregated from 'Helminthos porium' Canadian Journal of Plant Pathology, 28: (Issue 1, Supplement 1) S210S220

Straka, B. F., P. H. Cooper, \& B. A. Body. (1989). Cutaneous Bipolaris spicifera infection. Arch. Dermatol. 125:1383-6.

Stringer, S. P., and M. W. Ryan. (2000). Chronic invasive fungal rhinosinusitis. Otolaryngol. Clin. N. Amer. 33:375-387

Tan, Y.P., Madrid, H., Crous, P.W., Shivas, R.G. (2014). Johnalcornia gen. et. comb. nov., and nine new combinations in Curvularia based on molecular phylogenetic analysis. Australasian Plant Pathology 43:589-603.http://dx.doi.org/10.1007/s13313-0140315-6

Tazick Z. \& Tajick Ghanbary, M.A. (2013). Taxonomic position of Bipolaris oryzae among other Cochliobolus species using Ribosomal region and some Protein Coding genes. Research Journal of Recent Sciences. 2:212-216

Tsuda, M. \& Ueyama, A . (1981). Pseudocochliobolus austra-liensis. the ascigerous state of Bipolaris australiensis. Mycologia 73:88-96

Tsuda, M. \& Ueyama, A. (1983). Pseudocochliobolus pallescens and variability of conidium morphology. Mem. Col/.Agric. Kyoto Univ. 122:85-91 
Tsuda, M. ; Ueyama, A . \& Nishihara, N. (1977). Pseudocochliobolus nisikadoi. The perfect state of Helminthosporium coicis. Mycologia 69:11091120

Wakker, J.H. \& Went F.A.F.C.(1899). Overzicht van de Ziekten van het suikerriet op Java. Mededeelingen van het Proefstation Oost-Java (New Series) 22:11

Walsh, T.J. \& Groll, A.H.(1999). Emerging fungal pathogens: evolving challenges to immunocompromised patients for the twenty first century. Transpl. Infect. Dis. 1:247-261
Yanagihara M, Kawasaki M, Ishizaki H, Anzawa K, Udagawa S, et al. (2010). Tiny keratotic brown lesions of the interdigital web between the toes of a healthy man caused by Curvularia species infection and a review of cutaneous Curvularia infections. Mycoscience 51:224-233

Zhang, Y.; Schoch, C.L.; Fournier, J.; Crous, P.W. et al., (2009). Multilocus phylogeny of Pleosporales: a taxonomic, ecological and evolutionary re-evaluation. Studies in Mycology 64:85-102

Zhang, Y.; Crous, P.W.; Schoch, C.L. \& Hyde, K.D. (2012). Pleosporales. Fungal Diversity 53:1-221 